\title{
Intermediates in dioxygen activation by methane monooxygenase: A QM/MM study
}

\author{
David Rinaldo $†$, Dean M. Philipp ${ }^{\ddagger}$, Stephen J. Lippard ${ }^{\star}, \S$, and Richard A. Friesner ${ }^{\star}{ }^{\dagger}{ }^{\dagger}$ \\ Contribution from the Departments of Chemistry and Center for Biomolecular simulation, Columbia \\ University, New York, New York 10027, Schrodinger Inc, 101 SW Main Street, Portland, OR 97204, \\ Massachusetts Institute of Technology, Cambridge, Massachusetts 02139
}

\begin{abstract}
Protein effects in the activation of dioxygen by methane monooxygenase (MMO) were investigated by using combined QM/MM and broken-symmetry Density Functional Theory (DFT) methods. The effects of a novel empirical scheme recently developed by our group on the relative DFT energies of the various intermediates in the catalytic cycle are investigated. Inclusion of the protein leads to much better agreement between the experimental and computed geometric structures for the reduced form $\left(\mathrm{MMOH}_{\mathrm{red}}\right)$. Analysis of the electronic structure of $\mathrm{MMOH}_{\text {red }}$ reveals that the two iron atoms have distinct environments. Different coordination geometries tested for the $\mathrm{MMOH}_{\text {peroxo }}$ intermediate reveal that, in the protein environment, the $\mu-\eta^{2}, \eta^{2}$ structure is more stable than the others. Our analysis also shows that the protein helps to drive reactants towards products along the reaction path. Furthermore, these results demonstrate the importance of including the protein environment in our models and the usefulness of the QM/MM approach for accurate modeling of enzymatic reactions. A discrepancy remains in our calculation of the Fe-Fe distance in our model of $\mathrm{H}_{\mathrm{Q}}$ as compared to EXAFS data obtained several years ago, for which we currently do not have an explanation.
\end{abstract}

\section{Keywords}

Soluble Methane Monooxygenase; Methylococcus-capsulatus Bath; Nonheme Diiron Enzymes; Dinuclear Iron Centers; DFT; Density Functional Theory; Catalytic Cycle; Dioxygen Activation; O Bond-Cleavage; Intermediate Q; Peroxide Intermediate

\section{Introduction}

Soluble methane monooxygenase (sMMO) is a multicomponent enzyme complex that catalyzes the oxidation of methane to methanol in methanotrophic bacteria such as Methylococcus capsulatus (Bath) and Methylosinus trichosporium OB3b (Scheme 1): ${ }^{1-8}$

The complex is at present believed to involve a minimum of three components. The hydroxylase $(\mathrm{MMOH})$ catalyzes the oxidation reaction at a non-heme, carboxylate bridged dinuclear iron center held within a four-helix bundle. The reductase component (MMOR) is a flavin- and ferredoxin-containing protein that transfers electrons from NADH to reduce the diiron center of $\mathrm{MMOH}$ to its $\mathrm{Fe}$ (II)-Fe(II) state. Component $\mathrm{B}$ is a cofactorless protein required

\footnotetext{
* To whom correspondence should be adressed. E-mail: rich@chem.columbia.edu, lippard@mit.edu.

$\dagger$ Columbia University.

†Schrödinger Inc.

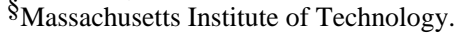


for efficient catalysis that also serves several regulatory roles. A fourth component, MMOD, has recently been characterized. Its function is still unclear, but it binds to $\mathrm{MMOH}$ and is a potent inhibitor of sMMO. It has been proposed to play a role in the assembly of the $\mathrm{MMOH}$ diiron center. 9

An important reason for the attention devoted to sMMO is its ability to oxidize the C-H bond of methane selectively to methanol under ambient temperature and pressure conditions. The understanding of the mechanism by which the enzyme catalyzes this chemically challenging reaction would not only be of great academic interest but also of possible practical value for the biomimetic design of new catalysts for the industrial conversion of methane to methanol. 10-12 Substantial advances in the understanding of this mechanism at an atomic level have been accomplished these last years through structural and spectroscopic studies $1,3,6-8$ as well as computational investigations. $13-18$

The catalytic cycle of sMMO can formally be divided into two steps: dioxygen activation and substrate oxidation (Figure 1). $\mathrm{O}_{2}$ activation can occur once the diiron center in the resting, oxidized form $\mathrm{MMOH}_{\mathrm{Ox}}$ is reduced by $\mathrm{MMOR}$ to form $\mathrm{MMOH}_{\mathrm{red}}$. Then, diffusion of $\mathrm{O}_{2}$ to the hydroxylase active site leads to the formation of $\mathrm{MMOH}_{\text {superoxo, }}$, which has an $\mathrm{Fe}(\mathrm{II})-\mathrm{Fe}$ (III) $\left(\mathrm{O}_{2}{ }^{-}\right)$iron core. ${ }^{19}$ Subsequently, $\mathrm{MMOH}_{\text {superoxo }}$ converts to the diamagnetic peroxo compound $\left(\mathrm{MMOH}_{\text {peroxo }}\right)$, the first intermediate spectroscopically characterized in the cycle after $\mathrm{O}_{2}$ reacts with $\mathrm{MMOH}_{\text {red. }} 8,20-25$ Based on comparisons with synthetic model compounds, cis- $\mu-1,2$ peroxo, $\mu-\eta^{1}-\eta^{1}$ or end-on structures were suggested ${ }^{26-29}$ for $\mathrm{MMOH}_{\text {peroxo }}$, whereas a $\mu-\eta^{2}-\eta^{2}$ butterfly structure has been proposed based on results from DFT studies. ${ }^{16,19}$ The last step in dioxygen activation yields intermediate $\mathrm{Q}\left(\mathrm{MMOH}_{\mathrm{Q}}\right)$. This compound harbors two high-valent, antiferromagnetically-coupled, $\mathrm{Fe}(\mathrm{IV})-\mathrm{Fe}(\mathrm{IV})$ atoms in nearly equivalent environments. $20,21,30,31 \mathrm{~A} \mathrm{Fe}(\mathrm{IV})_{2}-(\mu-\mathrm{O})_{2}$ diamond core with a short $\mathrm{Fe}-$ Fe distance has been proposed for this intermediate based on an EXAFS study. ${ }^{31}$ This intermediate reacts to convert methane into methanol yielding $\mathrm{MMOH}_{\mathrm{Ox}} \cdot 21,23,25,32$ The final steps of the mechanism, in which a hydrogen is abstracted from substrate, followed by recombination of the substrate with the resulting $\mathrm{OH}$ moiety in the core to produce hydroxylated product (methanol, in the case of a methane substrate) have been discussed extensively in previous work. $5,8,14,33-40$ In ref. [ $\left.{ }^{42}\right]$, this reaction is modeled using quantum dynamical methods, and both concerted and "radical rebound" mechanisms (the latter involving a very short lived bound radical species) are shown to contribute to the reaction pathway. We shall not discuss substrate oxidation further in the present paper, which is focused on dioxygen activation.

Extensive theoretical studies of dioxygen activation have been carried out in our group ${ }^{13}$, 14, 19, 41, 42 and others. ${ }^{43-48}$ Those studies were based on model clusters of different sizes, using mainly Density Functional Theory (DFT). Calculations using large ( 100 atom) models suggest that the protein plays a significant role in dioxygen activation, and that a more rigorous analysis of the protein contributions to the activation process would be useful. To date, the only quantum mechanics/molecular mechanics (QM/MM) calculations have focused on the study of $\mathrm{MMOH}_{\mathrm{ox}}$ and $\mathrm{MMOH}_{\text {red }}$ using the ONIOM method 49,50 and on the hydroxylation of several substrates by $\mathrm{MMOH}_{\mathrm{Q}}$ using the frozen orbital methodology. 39

The aim of the present paper is to analyze the structural and energetic effects of the protein on the different intermediates of the dioxygen activation pathway in the sMMO catalytic cycle. After describing the model and the methodology used for this study, the results obtained will be presented. They will be subsequently discussed in light of experimental data to gain insight into dioxygen activation mechanism and the role the protein matrix could play. To conclude, our results will be summarized. 


\section{Methods}

\section{Computational Methods}

QM/MM methods-Over the past decade, we have developed the QM/MM program QSite ${ }^{51}$ based on a frozen orbital approach. ${ }^{52-54}$ This program results from a tight coupling between Jaguar ${ }^{55}$ and the protein modeling program IMPACT ${ }^{56,57}$ developed by Levy and coworkers. The OPLS-AA ${ }^{58,59}$ molecular mechanics force field is used for the treatment of the MM part while the pure QM part was treated at the DFT-B3LYP level of theory, with details as discussed in the next section.

The methodology has been extensively tested and shown to give reliable results for the relative conformational energies of dipeptides ${ }^{52-54}$ and protonation energies of protein side-chains. 52,53 Moreover, it has successfully been applied to a number of biological systems ${ }^{13}$ such as the studies of the MMO hydroxylation step, ${ }^{39} \mathrm{P} 450,{ }^{60,} 61$ hemerythrin, ${ }^{62}$ triosephosphate isomerase (TIM), ${ }^{63}$ class C $\beta$-lactamase and Penicillin binding protein (PBP). ${ }^{39}$ The errors resulting from the QM/MM interface are quite small in an absolute sense $(\sim 0.5 \mathrm{kcal} / \mathrm{mol})$ and are expected to be unimportant as compared to intrinsic errors in the DFT methodology. 52 , 53

The antiferromagnetic coupling of the two iron atoms of intermediates in the catalytic cycle requires the use of unrestricted DFT (UDFT) methods to obtain reliable models. Until now this feature was not implemented into QSite and we therefore had to resort to a thermodynamic cycle, presented in Supporting Information, to get proper energetics. In the present study, the $\mathrm{QM} / \mathrm{MM} / / \mathrm{UDFT}$ scheme recently implemented into $\mathrm{QSite}^{64}$ has been used; the results obtained are compared to those generated using the previous scheme. The good agreement generally obtained between the two approaches validates the thermodynamic cycle used in our previous QM/MM studies. ${ }^{62,} 65$

QM methods-The core computational method chosen for this study is density functional theory (DFT) ${ }^{66}$ with the hybrid functional B3LYP. ${ }^{67-69}$ An unrestricted DFT (UDFT) methodology was employed to model spin polarization efficiently for open shell orbitals of both irons. This method enables modeling of antiferromagnetic (AF) coupling between the two Fe atoms by the use of a broken symmetry (BS) wave function. The Jaguar ${ }^{55}$ suite of $a b$ initio quantum chemical programs was used for all standalone QM calculations. This program using pseudospectral methods is particularly efficient for treating large size systems such as those found in biology 70,71 and its high-quality initial-guess wavefunctions for metals are very useful for studying bioinorganic systems. ${ }^{72,73}$

The choice of the basis set is also an important issue in computational studies. Our previous studies have shown that geometry optimizations using a mixed basis set, such as LACVP**74-76 for metals, $6-31 \mathrm{G} *$ on core atoms and $6-31 \mathrm{G}$ on the remaining atoms, gives reasonable results. For this study we used LACVP** for metals and 6-31G* on other atoms for consistency with $\mathrm{QM} / \mathrm{MM}$ calculation, since frozen orbitals are only available with the 6-31G* basis set. Accurate energy determinations require single point calculations with larger basis sets of triple- $\zeta$ quality in the diiron core, such as the scheme we have previously used with LACV3P** on metals, cc-pVTZ(-f) ${ }^{77}$ on core atoms and 6-31G** otherwise. We also add diffuse functions (cc-pVTZ(-f)++) onto both atoms of dioxygen because these atoms are strongly negatively charged in $\mathrm{MMOH}_{\mathrm{Q}}$. The results shown below indicate that the enhancement of the basis set on the core oxygen atoms yields improved results for the relative energetics of the various intermediates in the catalytic cycle.

Vibrational frequency calculations are highly computationally demanding tasks for big models. It is therefore necessary to use smaller models with lower quality basis sets for this purpose. 
In the present work, the LACVP**/6-31G** basis set was used for the core atoms and 6-31G was used otherwise.

Finally, we have recently developed a novel scheme for correcting errors in DFT energetics based on localized orbital corrections (LOC). ${ }^{78}$ When applied to a data set of 222 molecules containing first and second row atoms for which accurate enthalpies of formation, ionization potentials, electron affinities or proton affinities are experimentally well known (G3 dataset $^{79}$ ), the mean absolute deviation (MAD) versus experiment for the B3LYP version of the methodology (B3LYP-LOC) is $0.8 \mathrm{kcal} / \mathrm{mol}$, as compared to the MAD of $4.8 \mathrm{kcal} / \mathrm{mol}$ obtained for B3LYP alone. The methodology at present has only been robustly optimized and tested for first and second row atoms, but we can make a simple extension to apply it to the relative energetics of the various species involved in the $\mathrm{MMOH}$ catalytic cycle. We investigate the effects of these corrections for intermediates in MMO dioxygen activation. Although more work is required to achieve quantitatively accurate parametrization for transition metals, the localized corrections in their current form appear to provide significantly improved results for the relative energetics of the $\mathrm{MMOH}_{\mathrm{Q}}$ and $\mathrm{MMOH}_{\text {peroxo }}$ states, as revealed by comparisons to experimental data.

\section{Physical Model}

Our $\mathrm{QM} / \mathrm{MM}$ models are based on the $\mathrm{QM} / \mathrm{MM}$ structure of $\mathrm{MMOH}_{\mathrm{Q}}$ built in our previous study; 65 this structure in turn was initially derived starting from the crystal structure of the oxidized form. ${ }^{80,81}$ Due to the fact that the QM/MM code QSite $^{64}$ was only able to handle at most 8000 atoms, and in order to restrict computational effort, only residues and water molecules within $35 \AA$ of the active site of an $\alpha$ subunit of the $\alpha_{2} \beta_{2} \gamma_{2}$ MMOH were included in our calculations (Figure 2). To mimic solvent screening, all surface residues not engaged in salt bridges were neutralized. The QM region includes Glu 114, Glu144, His 147, Glu 209, Glu 243, His 246, a water molecule, and the diiron core, including dioxygen- or solvent-derived ligands when present. Backbone cuts were performed for both His 147 and His 246, whereas side chain cuts were used for the other residues. It should be noted that in our previous calculations, side chain cuts were also used for both histidines. However, our QM/MM//RDFT calculations revealed that important forces are exerted on the frozen bonds of the histidines. Such important forces on the QM/MM boundaries might generate artifacts in the energy. Although these errors should cancel by the use of the thermodynamic cycle in QM/MM//RDFT calculations, they may be more important in the QM/MM//UDFT scheme.

For the final system, the QM part and the whole QM/MM model were both neutral. The initial guess geometries of each intermediate were setup by modifying the diiron core and, when needed, Glu 243 in our model of $\mathrm{MMOH}_{\mathrm{Q}}$ to match better the geometries of the pure QM models obtained in our previous study. ${ }^{19}$ This task was performed by using the program Maestro, ${ }^{83}$ superimposing the $\mathrm{QM}$ cluster onto the $\mathrm{MMOH}_{\mathrm{Q}}$, changing distances and angles for the diiron core, and only modifying dihedral angles for Glu 243.

Pure QM calculations were carried out by taking the $\mathrm{QM}$ regions obtained in the $\mathrm{QM} / \mathrm{MM}$ calculations, cutting the models between the $\mathrm{C}_{\alpha}$ and the $\mathrm{C}_{\beta}$, and then capping the dangling bonds with hydrogen atoms. Frequency calculations were performed on medium-sized models ( $\sim 50$ atoms) derived from the QM/MM//RDFT structures, modeling glutamates by acetates and histidines by imidazoles. All zero point energies (ZPE) and thermochemical corrections were derived from these calculations performed after optimization of the capping hydrogen atoms and without frequency scaling. 


\section{Results}

\section{Geometries and electronic structures of reaction cycle compounds}

In this section, we analyze, for each compound of the catalytic reaction cycle, the geometry and electronic structure obtained to characterize the effect of the protein matrix and to determine the state of the species we are proposing.

Reduced form-The reduced form was modeled with two ferromagnetically coupled, high spin $(\mathrm{S}=2)$ iron(II) atoms in agreement with experimental evidence $21,84-86$ and previous theoretical results. ${ }^{19}$ After QM/MM optimization, the structure obtained gives RMSDs for heavy atoms of the diiron cluster and the liganded side chains of $0.35 \AA$ and $0.33 \AA$, respectively, with the crystal structures ${ }^{87}$ of the two protomers (the RMSD between the protomers' crystal structures is $0.15 \AA$ ). The $\mathrm{QM} / \mathrm{MM}$ model for the reduced structure of the enzyme is in very good agreement with experiment (Figure 3 ). This result contrasts with the pure QM calculation using a large cluster model, for which a RMSD of $0.99 \AA$ was found for almost the same heavy atoms as in the QM/MM for RMSD calculation.

The distance between $\mathrm{Fe}(\mathrm{II})$ ions reflects dramatically improved agreement between the QM/ $\mathrm{MM}$ and the experimental structures. In our calculation, a distance of $3.29 \AA$ was found between iron atoms, comparable to the experimental distance of 3.27-3.31 $\AA$ (Table 1). In contrast, in the pure QM calculation, the distance was $3.64 \AA$, clearly beyond the range of experimental and theoretical errors, as noted in our previous papers. ${ }^{19,} 41$ The distances between the iron and coordinated atom of the various protein and solvent-derived ligands are qualitatively similar in both the QM/MM and the pure QM models when compared to experiment. However, a more quantitative examination of the results reveals the deviation of selected distances between the QM/MM models and the crystallographic structure to be close to the deviation observed between the two crystallographic protomers, whereas the deviation obtained with the QM model was almost twice as large (Table 1). A closer analysis shows that the poorer RMSD obtained with the QM model is mainly due to contributions from the bridging water molecule O14 (Figure 3) and to the oxygen O11 from Glu 243. It is also interesting to note that the structural agreement of the $\mathrm{QM} / \mathrm{MM}$ model is better with protomer $\beta$ than with protomer $\alpha$ (data not shown), and that this discrepancy is also due to O11 (Glu 243), O13 (axial water) and $\mathrm{O} 14$ (bridging water). Moreover, in protomer $\alpha$, the water molecule O14 (Figure 3) is hydrogen bonded to both Glu 209 and to another water molecule located $2.96 \AA$ away, whereas in protomer $\beta$ the second water is farther away in the pocket (4.90 $\AA$ ), precluding formation of a hydrogen bond with O14. In our QM/MM models the second water is not included. Thus, the choice of our model, structurally closer to protomer $\beta$, could explain its deviation from protomer $\alpha$. These results also show that the geometry of the reduced state, and particularly the distances between iron ions and water molecules, are strongly dependent on the solvent hydrogen-bonding network, supporting the proposal that this network could play an important role during the reduction of $\mathrm{MMOH}_{\mathrm{Ox}} \cdot{ }^{44,45}$ To test this hypothesis, we have built a new model including, in the MM region, the two water molecules present in the crystal structure of protomer $\alpha$. The results obtained (data not shown) improved the agreement with the first-shell distances of protomer $\alpha$ (MAD of $0.142 \AA$ ) as well as the distance between $\mathrm{Fe} 1$ and $\mathrm{O} 14$. Interestingly, in presence of the new water molecules, Glu 209 and $\mathrm{Fe} 2$ are displaced whereas the other ligands are minimally perturbed (Figure 4 ). This effect is consistent with the proposed reduction mechanism, ${ }^{45}$ and is also in good agreement with the fact that $\mathrm{Fe} 2$ is more labile than $\mathrm{Fe} 1$ in the reduced state. 87

The QM/MM model shows that the protein matrix is responsible for the short Fe-Fe distance in the reduced state. Indeed, all previous QM models have consistently computed a substantially larger iron-iron distance than those found experimentally, and including second sphere ligands or electrostatic effects of the protein and solvent in a continuum model, did not 
entirely solve this problem. $19,41,44,50$ To understand the origin of the short Fe-Fe distance found in the current study, we analyze our data and determine the forces acting on the various atoms of our $\mathrm{QM} / \mathrm{MM} / / \mathrm{RDFT}$ model. The calculations of forces were carried out in vacuum and with point charges in place of MM atoms to distinguish electrostatic from strain effects of the protein. Forces acting on residues were obtained by summing up forces acting on all atoms of each residue.

The results are presented in Table 2/Figure 5 and show that strain forces (arrows in black on the right) and, to a lesser extent total forces (yellow arrows on the left), tend to keep residues of the active site grouped around the iron ions and to compress the active site. This property is particularly true for residues Glu 114, His 147, Glu 209 and His 246. The case of Glu 243 is different, because the protein tends to move it away from the diiron core. This result is consistent with the fact that, in the oxidized form, this ligand is rotated and no longer bonded to both $\mathrm{Fe} 1$ and $\mathrm{Fe} 2$. The origin of protein forces tending to keep the active site of the reduced form compact and thus driving the large decrease in the iron-iron distance is probably the fourhelix bundle fold. Analysis shows that interactions leading to the contraction of the active site occur between helices B-C on one hand and E-F on the other hand (Figure 5 and Table 2). But it must be noted that, even if these interactions can at least partly explain the decreased $\mathrm{Fe}-\mathrm{Fe}$ distance, interactions in the orthogonal direction (i.e. B-E and C-F) would be more efficient since they would be collinear with the iron-iron vector.

Forces exerted by the protein on each atom (data not shown) show very important forces of opposite directions on $\mathrm{N} \varepsilon_{2}$ and $\mathrm{H} \varepsilon_{2}$ of both histidines. This result is probably due to the wellconserved aspartates (Asp 143, Asp 242), hydrogen bonded to histidines, that attract Hع2 while the protein backbone tends to keep N $\varepsilon 2$ atoms in place. This observation emphasizes the role of Asp 143 and Asp 242 as noted in our previous paper, and which were included in our cluster models therein. ${ }^{41}$

To determine the energy the protein has to expend to keep the iron atoms at a shorter distance than in the QM models, we carried out a QM optimization of the capped QM region of our QM/MM model, first constraining the positions of the iron ions and then allowing a full optimization. The results show that constraining the iron-iron distance at the value of our QM/ MM model has a cost of $9.7 \mathrm{kcal} / \mathrm{mol}$. The difference between the $\mathrm{QM}$ and QM/MM models is therefore not due to a flat potential energy surface along the iron-iron coordinate. Rather, the protein matrix effect is important energetically and the protein has to expand significant energy to keep the iron-iron distance at the experimentally observed value.

The electronic structure analysis of our model shows that there are 8 unoccupied low-energy beta-spin orbitals that are mainly centered on the iron ions. The beta-spin HOMO and HOMO-1 are also centered on $\mathrm{Fe} 1$ and $\mathrm{Fe} 2$ respectively (see detailed analysis in Supporting Information). Thus, the electronic structure of $\mathrm{H}_{\mathrm{red}}$ is consistent with two high-spin ferrous iron atoms. But, despite their common oxidation state, the electronic structure reveals that the two iron atoms are not equivalent. Indeed, the two iron atoms are in different environments (Figure 6), with $\mathrm{Fe} 1$ having an octahedral geometry and $\mathrm{Fe} 2$ being in a square pyramidal environment.

Reduced form without coordinated water $\left(\mathrm{H}_{\text {red-no-wat }}\right.$ - - Geometry optimization of the reduced form of the enzyme, after departure of the loosely coordinated water molecule trans to the histidines (O14), yields a QM/MM structure similar to that of the original reduced enzyme model; the RMSD between them (without O14) is only $0.12 \AA$ (Figure S-3).

Differences are mainly due to a slight increase in the Fe-Fe distance from $3.29 \AA$ to $3.38 \AA$, to a slight shift of Glu 243 so that the single-atom bridge between the two iron atoms is more effective, and to an important shift of the axial water on $\mathrm{Fe} 1(\mathrm{O} 13)$ due to an increase of the angle with His $147\left(\mathrm{O} 13-\mathrm{Fe} 1-\mathrm{N}_{\mathrm{His} 147}\right)$ from $92^{\circ}$ to $102^{\circ}$. This similarity is also reflected at the 
electronic level; the same electronic configuration as in the reduced state is found for the iron cations. Since the electronic structure of the iron atoms is not affected by the water departure, the water is only bound to iron cations through electrostatic interactions. Given the fact that these iron atoms are in a relatively low oxidation state, and are surrounded by negatively charged ligands, the weak coordination of the water molecule can be rationalized. The departure of the water is also correlated with an increased Fe-Fe distance, probably because the water molecule helps to reduce electrostatic repulsion between the iron atoms, allowing them to stay closer in the pure reduced form.

Attack of dioxygen: formation of the superoxo intermediate-The first step in dioxygen activation is formation of $\mathrm{H}_{\text {superoxo. This electron transfer process, which involves }}$ different spin coupling schemes and different geometries, has been extensively studied in our previous paper. ${ }^{19}$ We basically follow the lowest energy path that was found therein: binding of dioxygen to form the undecet $\mathrm{H}_{\text {superoxo }}(\mathrm{S}=5)$, then intersystem crossings (ISC) to yield $\mathrm{H}_{\text {superoxo }}$ in its triplet state $(\mathrm{S}=1)$ and then in its singlet state $(\mathrm{S}=0)$.

The structure of $\mathrm{H}_{\text {superoxo }}(\mathrm{S}=5)$ obtained at the QM/MM level is slightly different from the one obtained via pure QM calculations ${ }^{19}$ an RMSD between the two structures of $0.83 \AA$ is obtained for the active site atoms. This RMSD is primarily due to differences located on the ligands of $\mathrm{Fe} 2$, because Glu 243 and dioxygen are less tilted toward $\mathrm{Fe} 2$, in a way similar to what was found in our earlier study ${ }^{41}$ (with which it has a RMSD of $0.72 \AA$ ), and His 246 does not rotate as in the pure QM calculation. The Fe-Fe distance of $3.44 \AA$ is shorter than in our pure QM models (3.79 $\AA$ in $\left[{ }^{19}\right]$ and $3.71 \AA$ in $\left.\left[{ }^{41}\right]\right)$ therefore showing that the protein matrix tends also to decrease the Fe-Fe distance in the $\mathrm{H}_{\text {superoxo }}(\mathrm{S}=5)$ state. Analysis (see Supporting Information) shows that this state has an electronic structure intermediate between those of

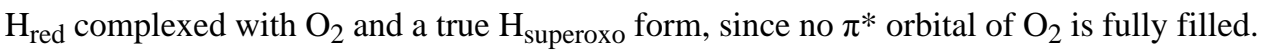
Similar electronic structures with intermediate characters have already been pointed out in metal-dioxygen complexes. 88

The QM/MM structure of the triplet $(\mathrm{S}=1) \mathrm{H}_{\text {superoxo }}$ is very similar to the one obtained for the undecet $(\mathrm{S}=5)$ state (RMSD of $0.10 \AA$ ). Electronic structure analysis (see Supporting Information) shows that the electron transfer occurs in this triplet state because the chargetransfer from $\mathrm{Fe} 2$ to dioxygen is much more important than in the undecet state. Thus, the electronic structure is consistent with a state mixing in approximately equal amounts those of a pure reduced enzyme state (no electron transfer to dioxygen) and a pure superoxo state (one electron transferred to dioxygen).

The structure of the singlet is closer to the structure of the undecet (RMSD of $0.04 \AA$ ) than the one of the triplet $(0.08 \AA)$. The electronic structure of this state of $\mathrm{H}_{\text {superoxo }}$ is compatible with a true superoxide species with the electron transferred to the dioxygen molecule coming from $\mathrm{Fe} 2$. This is consistent with the fact that dioxygen preferentially binds $\mathrm{Fe} 2$, and thus electron transfer from $\mathrm{Fe} 2$ is facilitated. It can therefore be noticed that, for this species, $\mathrm{Fe} 2$ appears to be less electrophilic than Fe1 while in a previous study 89 on $\mathrm{MMO}_{\mathrm{Q}}$ (vide infra) the reverse was observed. This is actually not inconsistent, because the iron atoms in these species are in different oxidation states and moreover, we have shown (vide supra) that in the reduced state the iron atoms experience different ligand fields. It is therefore difficult to predict the electrophilicity of $\mathrm{Fe} 1$ and $\mathrm{Fe} 2$ without taking into account the particular state of the catalytic cycle in question.

The peroxide intermediate-The next step involves a second electron transfer from Fe1 to the dioxygen molecule to yield a peroxide intermediate. We have previously proposed two possible structures for this intermediate based on pure QM calculations. ${ }^{19,41}$ We investigated both models with QM/MM, but also reconsidered two additional structures. All these 
possibilities are presented in Figure 7. It was previously shown, ${ }^{19}$ after extensive QM investigations, that for an $\sim 100$ atom model, the lowest energy structure was the $\mu-\eta^{2}, \eta^{2}$ butterfly arrangement in its singlet state. However, we investigated again all four alternatives at the QM/MM level to see whether the protein could change their relative energies. Moreover, we also investigated the possibility of a cis- $\mu-1,2$ coordination of peroxide to the iron atoms since it has been recently shown that this coordination geometry was favored in a ribonucleotide reductase variant. 90

The QM/MM $\mu-\eta^{2}, \eta^{2}$ butterfly structure displays a noticeable similarity to its pure QM counterpart (in both the undecet and singlet states); the RMSD between them is only $0.59 \AA$ for both states. The $\mathrm{Fe} 1-\mathrm{Fe} 2$ distance in the QM/MM model (3.48 $\AA$ ) is smaller than that in the undecet and singlet QM models (3.64 $\AA$ and 3.61 A respectively, Table 3 and Table S-3), and the value of the dihedral angle Fe1-O1-O2-Fe2 (defined in Figure 8) is $144.8^{\circ}$.

The $\mu-\eta^{2}, \eta^{1}$ (also called asymmetric APER ${ }^{19}$ ) structure proposed for $\mathrm{H}_{\text {peroxo }}$ is very similar structurally to the analogous geometry proposed for $\mathrm{H}_{\text {superoxo }}$. The main differences observed are:

- a more pronounced shift of Glu 243 in the peroxo species so that the oxygen bridges both irons more symmetrically.

- a slight shift of dioxygen closer to both iron atoms and mainly toward Fe1.

The QM/MM structure obtained here is slightly different from the pure QM model previously obtained (RMSD of $0.77 \AA$ ). The protein modestly decreases the iron-iron distance from 3.36 $\AA$ to $3.27 \AA$. The dihedral angle involving the peroxide moiety and the iron centers is $102.6^{\circ}$.

Two structures were tested for the cis- $\mu-1,2 \mathrm{H}_{\text {peroxo }}$ species. One $\left(A \mu-1,2 \mathrm{H}_{\text {peroxo }}\right)$ was based on the $\mu-\eta^{2}, \eta^{1} \mathrm{H}_{\text {peroxo }}$ (asymmetric structure: Aperoxo) and the other $\left(\mathrm{S} \mu-1,2 \mathrm{H}_{\text {peroxo }}\right.$ ) on the $\mu-\eta^{2}, \eta^{2}$ butterfly structure (Speroxo) (Figure 7). The QM/MM structure of $S \mu-1,2 \mathrm{H}_{\text {peroxo }}$ is very similar to that of the $\mu-\eta^{2}, \eta^{2}$ butterfly $\mathrm{H}_{\text {peroxo }}$ species with distances of $1.87 \AA$ between the closer oxygen atom of the peroxo moiety and both Fe1 and Fe2. The Fe-Fe distance increases from $3.48 \AA$ in the $\mu-\eta^{2}, \eta^{2}$ structure to $3.64 \AA$ in the $S \mu-1,2 \mathrm{H}_{\text {peroxo }}$ structure. This increase is relatively large compared to those for the other species and is probably due to the lack of a single-atom bridge between the iron atoms and the subsequent increased electrostatic repulsion between the two cations. This effect is more marked in the full QM calculation for which the Fe-Fe distance reaches $4.02 \AA$ in the $\mathrm{S} \mu-1,2$ structure compared to $3.61 \AA$ for $\mu$ $\eta^{2}, \eta^{2} \mathrm{H}_{\text {peroxo }}$ (Table 3). These results again emphasize the role of the protein, which tends to reduce the $\mathrm{Fe}-\mathrm{Fe}$ distance, and suggest that this structure should be relatively high in energy in the protein matrix given the significant difference between $\mathrm{QM}$ and QM/MM iron-iron distances.

For the $\mathrm{A} \mu-1,2 \mathrm{H}_{\text {peroxo }}$ structure, based on the results from model compounds, $26,91,92$ three kinds of conformers might be considered depending on the value of the dihedral angle defined by the irons and oxygen atoms (Figure 8). Our QM/MM calculations evaluated these three different conformers in the protein environment. The cis conformer (Figure 8) was discarded since it is higher in energy by $10-15 \mathrm{kcal} / \mathrm{mol}$ than its counterparts. The two gauche structures have similar energies, and their Fe-O-O-Fe units resemble the structure of a model compound studied by Kim and Lippard 26 in which the corresponding dihedral angles is $53^{\circ}$. In the discussion below, we only describe the lowest energy structure (top middle in Figure 8).

The correspondence between the structure of $A \mu-1,2 \mathrm{H}_{\text {peroxo }}$ and those of the $\mu-\eta^{2}, \eta^{2}$ $\mathrm{H}_{\text {peroxo }}$ and $\mu-\eta^{2}, \eta^{1} \mathrm{H}_{\text {peroxo }}$ is quite good. Their respective RMSDs are $0.24 \AA$ and $0.19 \AA$ ignoring the peroxide moiety and Glu 243 in the case of $\mu-\eta^{2}, \eta^{2} \mathrm{H}_{\text {peroxo }}$. This good agreement is also reflected by the Fe-Fe distance (Table 3 ), since the value in $\mathrm{A} \mu-1,2 \mathrm{H}_{\text {peroxo }}$ is essentially 
the same as found in $\mu-\eta^{2}, \eta^{2} H_{\text {peroxo }}$. Therefore, the $A \mu-1,2 H_{\text {peroxo }}$ structure seems to be a reasonable candidate for the $\mathrm{H}_{\text {peroxo }}$ intermediate in the protein environment. But the geometries of the peroxide moieties in the three structures are very different. The $\mathrm{A} \mu-1,2$ and $\mu-\eta^{2}, \eta^{1}$ structures display short oxygen-oxygen distances ( $1.33 \AA$ and $1.38 \AA$ respectively), whereas in the $\mu-\eta^{2}, \eta^{2}$ structure this distance is substantially greater $(1.49 \AA)$. Based on compounds present in the Cambridge Structural Database, ${ }^{93}$ these distances clearly indicate that the $A \mu-1,2$ and $\mu-\eta^{2}, \eta^{1}$ structures are more consistent with a superoxo species (1.33 $\AA$ ), whereas the peroxo $\mu-\eta^{2}, \eta^{2}$ structure actually resembles a peroxide $(1.45 \AA)$. This assignment is further supported by the electronic structure analysis below.

The singlet $\mu-\eta^{2}, \eta^{2}$ butterfly structure affords two pseudo-octahedral environments at the iron atoms. Five virtual orbitals are centered on each iron atom and one empty $\sigma^{*}$ orbital is centered on the dioxygen moiety. This electronic structure is consistent with two anti-ferromagnetically coupled high-spin Fe(III) atoms, as found experimentally, ${ }^{20,} 21$ in octahedral environments.

On the other hand, the electronic structure of $A \mu-1,2 \mathrm{H}_{\text {peroxo }}$ can best be described as intermediate between a superoxo and a peroxo species because the second electron transfer does not appear to have been completed. Analysis of the orbitals shows that a $\pi^{*}$ orbital of dioxygen is not totally filled and that $\mathrm{Fe} 1$ is still partly in its reduced state (see Supporting Information). Thus, $A \mu-1,2 \mathrm{H}_{\text {peroxo }}$ is more consistent with a superoxo structure with strong charge transfer from Fe1(II) to the dioxygen moiety. The electronic structures of the $\mu-\eta^{2}, \eta^{1}$ $\mathrm{H}_{\text {peroxo }}$ and $\mathrm{S} \mu-1,2 \mathrm{H}_{\text {peroxo }}$ species are also better described as a superoxo species (see Supporting Information).

To characterize further the differences between the $\mu-\eta^{2}, \eta^{2}$ butterfly and the cis- $\mu-1,2$ $\mathrm{H}_{\text {peroxo }}$ structures, we have also analyzed the frequencies corresponding to the $\mathrm{O}-\mathrm{O}$ and $\mathrm{Fe}-\mathrm{O}$ stretching modes for both ${ }^{16} \mathrm{O}_{2}$ and ${ }^{18} \mathrm{O}_{2}$ to determine the isotopic shift (a B3LYP/6-31G* scaling factor of $0.9614^{94}$ was used for all frequencies). In case of the cis- $\mu-1,2 \mathrm{H}_{\text {peroxo }}$, a $v$ $\left({ }^{16} \mathrm{O}-{ }^{16} \mathrm{O}\right)$ frequency of $1004 \mathrm{~cm}^{-1}$ was computed, compared to a value of $888 \mathrm{~cm}^{-1}$ for a model compound ${ }^{26}$ (Table 4). A shift of $48 \mathrm{~cm}^{-1}$ was found in the case of the doubly isotopically substituted ${ }^{18} \mathrm{O}_{2}$, in good agreement with the shift of $46 \mathrm{~cm}^{-1}$ observed experimentally. ${ }^{26}$ The $v\left(\mathrm{Fe}^{16} \mathrm{O}\right)$ frequency was computed to be $441 \mathrm{~cm}^{-1}$ with an isotopic shift of $20 \mathrm{~cm}^{-1}$, compared to $415 \mathrm{~cm}^{-1}\left[\Delta^{18} \mathrm{O}=11 \mathrm{~cm}^{-1}\right]^{26}$ for the experimental results. In case of the $\mu-\eta^{2}, \eta^{2} \mathrm{H}_{\text {peroxo }}$ structure, we obtained a $v\left({ }^{16} \mathrm{O}-{ }^{16} \mathrm{O}\right)$ frequency of $815 \mathrm{~cm}^{-1}$ and a $v\left(\mathrm{Fe}_{-}{ }^{16} \mathrm{O}\right)$ value of 544 $\mathrm{cm}^{-1}$ with isotopic shifts of $44 \mathrm{~cm}^{-1}$ and $15 \mathrm{~cm}^{-1}$ respectively. There is currently no model complex with this structure.

The higher $v\left({ }^{16} \mathrm{O}-{ }^{16} \mathrm{O}\right)$ frequency found for the cis- $\mu-1,2 \mathrm{H}_{\text {peroxo }}$ compared to the $\mu-\eta^{2}, \eta^{2}$ $\mathrm{H}_{\text {peroxo }}$ structure reveals its greater $\mathrm{O}-\mathrm{O}$ bond order, and thus supports the superoxide character revealed by the electronic structure analysis. Compared to experiment, our calculations reveal enhanced superoxide character for this structure in the protein. In order to investigate whether a basis set effect was responsible for this behavior, the QM/MM models for the cis- $\mu-1,2$ and the $\mu-\eta^{2}, \eta^{2} \mathrm{H}_{\text {peroxo }}$ models were optimized again by using the lacv $3 \mathrm{p}^{* *}$ basis set on iron atoms and the cc-pVTZ(-f)++ on both oxygen atoms of the peroxide. The frequency calculations were then performed with the same modifications to the usual basis set. The results obtained show that, from a structural point of view, the basis set has an effect since the peroxo oxygen-oxygen distance increases from $1.33 \AA$ to $1.37 \AA$ in case of the cis- $\mu-1,2 \mathrm{H}_{\text {peroxo }}$ and from $1.49 \AA$ to $1.51 \AA$ in the case of the $\mu-\eta^{2}, \eta^{2}$ structure. These results indicate that the superoxo character of the cis- $\mu-1,2 \mathrm{H}_{\text {peroxo }}$ is overestimated without the use of large basis sets (including diffuse functions) on the diiron core. Furthermore, the theoretical frequencies obtained with the large basis sets are in better agreement with experimental results on model compounds even without scaling (Table 4). For instance, the $v\left({ }^{16} \mathrm{O}-{ }^{16} \mathrm{O}\right)$ frequency of the cis- $\mu-1,2 \mathrm{H}_{\text {peroxo }}$ structure 
decreases to $975 \mathrm{~cm}^{-1}$ due to the decreased superoxo character, but it is still not enough to reach a good agreement with the model compound $\left(888 \mathrm{~cm}^{-1}\right)$.

The frequency obtained for the cis- $\mu-1,2 \mathrm{H}_{\text {peroxo }}$ structure indicates that it has a strong superoxo character, even when large basis sets are used. This frequency is intermediate between the ranges of experimental frequencies usually assigned to peroxo and to superoxo as defined by Suzuki et al. ${ }^{95}$ based on different molecular oxygen complexes.

Intermediate $\mathbf{Q}$-The last step of dioxygen activation involves reduction of $\mathrm{H}_{\text {peroxo }}$ by the transfer of two electrons from iron atoms leading to the cleavage of the $\mathrm{O}-\mathrm{O}$ bond. The resulting di $\left(\mu\right.$-oxo)diiron(IV) structure $\left(\mathrm{H}_{\mathrm{Q}}\right)$ can formally be described as two $\mathrm{O}^{2-}$ ions coordinated to two $\mathrm{Fe}(\mathrm{IV})$ cations.

The main difference observed between structures obtained at the QM/MM level and at the QM level (RMSD of $0.73 \AA$ between them) are rotations of Glu 209 and Glu 114 leading to slight differences in the structure of the $\mathrm{Fe}_{2}(\mu-\mathrm{O})_{2}$ quadrilateral. Interestingly, in the QM/MM model, the $\mathrm{Fe}-\mathrm{O}$ distances appear to be somewhat asymmetric with the oxygen atoms both being closer to Fe1 than to Fe2, with average distances of $1.75 \AA$ and $1.90 \AA$ respectively (Figure 9). Asymmetry has also been reported from an analysis of the results of EXAFS experiments on $\mathrm{H}_{\mathrm{Q}} \cdot{ }^{31}$ Our calculations reveal that the two iron centers are not equivalent, indicating a slightly diminished (between $\mathrm{Fe}^{\mathrm{IV}}$ and $\mathrm{Fe} \mathrm{III}^{\mathrm{II}}$ ) oxidation state for $\mathrm{Fe} 2$ as compared to $\mathrm{Fe} 1\left(\mathrm{Fe}^{\mathrm{IV}}\right)$. This results from the fact that $\mathrm{Fe} 2$ appears to be slightly more electrophilic than $\mathrm{Fe} 1$ and thus attracts more the electrons from the oxygen atoms. This is consistent with our previous study 89 showing that $\mathrm{Fe} 2$ is actually the first iron atom reduced during the reaction between $\mathrm{H}_{\mathrm{Q}}$ and methane. The iron-iron distance is larger in the QM/MM models (2.84 $\AA$ ) than in the QM one $(2.70 \AA)$ and significantly larger than found by the analysis of the EXAFS data $(2.46 \AA) .31$ Our QM models have also shown that the singlet state has nearly symmetric Fe-O distances $(1.76 \AA$ and $1.82 \AA)$, whereas in the nonet state these bonds were very asymmetric $(1.69 \AA$ and $2.13 \AA$ ). The analysis indicates this result is derived from a higher oxidation level of Fe1 compared to $\mathrm{Fe} 2$ (formally a $\mathrm{Fe}^{\mathrm{V}}-\mathrm{Fe}^{\mathrm{III}}$ core) (see Supporting Information).

The electronic structure obtained for the singlet state of $\mathrm{H}_{\mathrm{Q}}$ is in good agreement with that expected for a di( $\mu$-oxo)diiron(IV) species and has been presented in a previous paper. 89 Nonetheless, compared to the $\mu-\eta^{2}, \eta^{2}$ butterfly $\mathrm{H}_{\text {peroxo }}$, strong delocalization of oxo electrons onto the iron atoms can be noticed, supporting an increased covalency between iron and oxygen atoms as has recently been proposed based on oxoiron(IV) model compounds. 96,97

\section{Energetic analysis}

In this section we analyze the energies of our computed reaction cycle components comparing relative energies for QM/MM with the purely QM models discussed in ref. [ $\left.{ }^{19}\right]$. We consider all states discussed above with the exception of that in which the water is displaced from the cavity prior to binding of dioxygen. This state is not experimentally accessible, and there are considerable complexities in dealing with the free energies of binding of small molecules to the protein. Furthermore, examination of the reduced MMO crystal structure reveals a different number of waters in the cavities of the two $\alpha$-subunit protomers, and the presence or absence of a second water molecule would have a significant effect on the calculated free energies of the state in question.

Along the same lines, we note that energy differences between the reduced enzyme and oxygenated intermediates also involve an estimation of the binding affinity of dioxygen to the protein. As indicated above, these quantities are subject to some uncertainty, so our expectation is that the calculation of the relative energy of the reduced enzyme compared to the other species will have increased error bars due to these issues. 
The large basis set QM/MM//UDFT single point energies, supplemented by frequency calculations on models as discussed above, provide the starting point for our energetic analysis. We have additionally investigated the effects of two types of correction terms. Firstly, we constructed a Heisenberg spin model in order to improve the relative energetics of AF spin states as modeled via broken symmetry and unrestricted wave functions; details of the methodology are given in Supporting Information. Secondly, we introduce a new set of corrections based on the localized orbital correction (LOC) approach discussed earlier. LOC assigns correction parameters for atomic hybridization states and for each electron pair in a bonding orbital, depending upon the type of bond and its local environment. Our assessment of the relative energetics of structures in the MMO catalytic cycle utilizes the following key parameters of the methodology, derived from fitting to the G3 data set as discussed in detail in ref. $\left[{ }^{78}\right]$ :

1. An $\mathrm{O}$ atom is assigned a correction factor of $1.8 \mathrm{kcal} / \mathrm{mol}$ when $\mathrm{sp}^{3}$ hybridized, and $1.0 \mathrm{kcal} / \mathrm{mol}$ when $\mathrm{sp}^{2}$ hybridized.

2. An ordinary $\mathrm{O}-\mathrm{O}$ single bond is assigned a correction factor of $-2.0 \mathrm{kcal} / \mathrm{mol}$ and a double bond, $-1.0 \mathrm{kcal} / \mathrm{mol}$.

3. An ionic bond ( $\mathrm{NaCl}$ is the prototypical example) is assigned a correction factor of $-4.5 \mathrm{kcal} / \mathrm{mol}$. This parameter works remarkably well for a wide range of "ionic" pairs, not only $\mathrm{NaCl}$ but formal charge separations assigned on the basis of classical valence bond theory as, for example, in CO or ozone. The success in describing ozone is particularly relevant to the present task; the corrected B3LYP-LOC atomization energy error is only $-1.87 \mathrm{kcal} / \mathrm{mol}$ whereas the B $3 L Y P$ error is $8.6 \mathrm{kcal} / \mathrm{mol}$.

The physical rational for these corrections is based on the localized nature of the residual errors in DFT methods, which arise from erroneous treatment of nondynamical correlations of both unpaired and paired electrons. For electron pairs, B3LYP underestimates nondynamical correlation when the "size" of the localized orbital containing the pair is "small" compared to the bond length. The discrepancy is particularly large for ionic bonds with long distances, as is the case here for a subset of the Fe-O interactions. The number of ionic (non-covalent) electron pairs on the core oxygen atoms increases as one goes from $\mathrm{H}_{\text {superoxo }}$ (one) to $\mathrm{H}_{\text {peroxo }}$ (two) to $\mathrm{H}_{\mathrm{Q}}$ (four) and hence, according to the theory, the total energy of these species is increasingly overestimated. We argue below that the correction terms restore the proper relative energetics of our intermediates.

Results obtained from our QM/MM B3LYP calculations using the high level basis set with diffuse functions on dioxygen atoms are presented in Table 5 for all species found to be relevant at a lower computational level. The Heisenberg exchange coupling constants (Table 6) were calculated for $\mathrm{H}_{\text {red }}, \mathrm{H}_{\text {peroxo }}$ and $\mathrm{H}_{\mathrm{Q}}$. Moreover, in the case of $\mathrm{H}_{\text {superoxo }}$, the formula for spinprojection cannot be applied because the metals are not equivalent, but the error induced by neglecting spin projection should be small since the differences between high-spin and broken symmetry energies are rather insignificant (less than $1 \mathrm{kcal} / \mathrm{mol}$ ).

The relative energies of intermediates found in our QM/MM calculations, presented in Figure 10 , are qualitatively comparable with those along the best path previously identified. ${ }^{19}$ Some quantitative differences emerged, however, between the present $\mathrm{QM} / \mathrm{MM}$ study and our previous purely QM models.

First, we re-evaluated $\mu-1,2$ models for the controversial structure of the $\mathrm{H}_{\text {peroxo }}$ intermediate. Our results show that the $A \mu-1,2 \mathrm{H}_{\text {peroxo }}$ structure appears to be slightly higher in energy compared to the $\mu-\eta^{2}, \eta^{2}$ species (Table 5). Nonetheless, given the relatively small energy difference, this structure might be a putative intermediate between $H_{\text {superoxo }}$ and the $\mu-\eta^{2}, \eta^{2}$ form of $\mathrm{H}_{\text {peroxo. }}$. On the other hand, the $\mathrm{S} \mu-1,2 \mathrm{H}_{\text {peroxo }}$ species which lacks a bridging atom 
between the iron atoms, was computed to be much higher in energy than the $\mu-\eta^{2}, \eta^{2}$ structure at the $\mathrm{QM} / \mathrm{MM} / \mathrm{RDFT}$ level. This species was therefore discarded as a possible intermediate in the reaction mechanism and further calculations were not performed on it.

The second main difference between the $\mathrm{QM}$ and $\mathrm{QM} / \mathrm{MM}$ calculations is related to the relative energy between $\mu-\eta^{2}, \eta^{2} \mathrm{H}_{\text {peroxo }}$ and $\mathrm{H}_{\mathrm{Q}}$. Actually, in our QM/MM calculations (Table 5), $\mathrm{H}_{\mathrm{Q}}$ is higher in energy than $\mathrm{H}_{\text {peroxo }}$ by $0.7 \mathrm{kcal} / \mathrm{mol}$. This result is surprising because experimentally $\mathrm{H}_{\mathrm{Q}}$ can be kinetically trapped 3,8 and the reaction should thus be exothermic, presumably by a significant margin compared to $\mathrm{kT}$, or one would see residual population of $\mathrm{H}_{\text {peroxo }}$ experimentally. Previous authors using different computational models have encountered the same problem. ${ }^{98,99}$ Moreover, our new results are in contradiction to our previous findings reported in ref. $\left[{ }^{19}\right]$, in which $\mathrm{H}_{\mathrm{Q}}$ was $11.7 \mathrm{kcal} / \mathrm{mol}^{19}$ lower in energy than $\mathrm{H}_{\text {peroxo }}$. The reason for this discrepancy has been identified as a structural difference between our QM/MM models of $\mathrm{H}_{\mathrm{Q}}$ and the large QM model previously employed. ${ }^{19}$ In our QM models, Asp 242-Glu 243 peptide displays a different conformation than that in the crystallographic structures $80,81,87$ or other QM or QM/MM models (See Supporting Information Figure S-17). As pointed out by Siegbahn, 100 this previous conformation allows the formation of a new hydrogen bond between the dangling oxygen atom of Glu 243 and a backbone N-H unit. To check whether this new hydrogen bond was responsible for the significant stabilization of $\mathrm{H}_{\mathrm{Q}}$ over $\mathrm{H}_{\text {peroxo }}$ in our large $\mathrm{QM}$ models in ref. $\left[{ }^{19}\right]$, we constructed a big QM model of $\mathrm{H}_{\text {peroxo }}$ with the same backbone conformation. Our results reveal that this hydrogen bond also strongly lowers the energy of $\mathrm{H}_{\text {peroxo }}$. However, the present QM/MM calculations indicate that such a hydrogen bond does not form inside the protein for either $\mathrm{H}_{\mathrm{Q}}$ or $\mathrm{H}_{\text {peroxo }}$ due to the constraints and hydrogen bond network generated by the protein fold which are not present in the purely $\mathrm{QM}$ models. Thus the overstabilization of $\mathrm{H}_{\mathrm{Q}}$ due to this hydrogen bond is no longer possible in the QM/MM models, and $\mathrm{H}_{\mathrm{Q}}$ becomes slightly less stable than $\mathrm{H}_{\text {peroxo }}$ when calculated with the B3LYP density functional, as indicated above.

Because the above QM/MM results for the relative energies of $\mathrm{H}_{\text {peroxo }}$ and $\mathrm{H}_{\mathrm{Q}}$ were in disagreement with experiment, we investigated whether this discrepancy could be explained by the intrinsic errors of B3LYP. We applied the B3LYP-LOC scheme outlined above, with simple approximations as discussed in Supporting Information, to the results obtained for all the structures previously found to be relevant for the dioxygen activation reaction. These findings are presented in Table 7. As can be seen, the corrections of the B3LYP-LOC scheme favor the dioxygen activation by $\mathrm{MMO}$ as a whole, because the series of intermediates contains an increasing component of charge transfer from the iron to the dioxygen atoms in the core (Figure 10). The correction is particularly important for the relative energies of $\mathrm{H}_{\text {peroxo }}$ and $\mathrm{H}_{\mathrm{Q}}$. We can see that, with B3LYP-LOC, $\mathrm{H}_{\mathrm{Q}}$ is much more stabilized than $\mathrm{H}_{\text {peroxo }}$. Based on this preliminary analysis, B3LYP errors may be the reason for the lower energy of $\mathrm{H}_{\text {peroxo }}$ compared to $\mathrm{H}_{\mathrm{Q}}$ reported above. We hypothesize that these errors mainly arise due to underestimation of the contribution of ionic character bonds in using standard B3LYP results and the fact that these bonds are strongly involved in the dioxygen activation reaction.

\section{Discussion}

\section{Nature of the $\mathrm{H}_{\text {peroxo }}$ intermediate}

Several structures for $\mathrm{H}_{\text {peroxo }}$ have been investigated in this study. The results obtained allow us to discard the $\mathrm{S} \mu-1,2(1) \mathrm{H}_{\text {peroxo }}$ based on its high energy compared to the other structures. It lacks a bridging ligand between the iron atoms that stabilizes the other structures. The QM/ $\mathrm{MM} / \mathrm{RDFT}$ results show that the $\mu-\eta^{2}, \eta^{2} \mathrm{H}_{\text {peroxo }}$ and the $A \mu-1,2 \mathrm{H}_{\text {peroxo }}$ species are very similar in energy, whereas the $\mu-\eta^{2}, \eta^{1} \mathrm{H}_{\text {peroxo }}$ is slightly higher. Finally, our QM/MM//UDFT results indicate that the $\mu-\eta^{2}, \eta^{2} \mathrm{H}_{\text {peroxo }}$ is actually lower in energy than the $A \mu-1,2 \mathrm{H}_{\text {peroxo }}$ by $2.8 \mathrm{kcal} / \mathrm{mol}$ in the protein environment. 
In the case of a ribonucleotide reductase variant,, 90 the peroxo intermediate has a cis- $\mu-1,2$ peroxo diiron(III) core structure. Although our pure QM calculations are compatible with such a hypothesis for $\mathrm{H}_{\text {peroxo }}$, QM/MM models reveal that this structure is destabilized in the protein. Analysis shows that the main differences involve the two histidines which rotate in the QM model, and Glu 243, which forms a much better bridge in the QM structure. An important difference between the QM and QM/MM models is the $0.10 \AA$ A shorter iron-iron distance in the latter. This distance is consistent with the effect of the protein observed for all the species involved in the $\mathrm{O}_{2}$ activation, from which, the energy discrepancy between the QM and QM/ $\mathrm{MM}$ models can be rationalized. The energy of the $\mathrm{A} \mu-1,2 \mathrm{H}_{\text {peroxo }}$ structure should be more sensitive to this distance because the overlap between the peroxo and iron orbitals will depend strongly on it. This point is supported by the fact that the $\mathrm{A} \mu-1,2 \mathrm{H}_{\text {peroxo }}$ with a cis conformation ( $\phi \sim 0$ in Figure 8$)$ is strongly destabilized by including the protein in our models. Therefore, the fact that the $\mu-\eta^{2}, \eta^{2}$ core structure is preferred over the $A \mu-1,2 \mathrm{H}_{\text {peroxo }}$ structure in MMOH appears to be a consequence of the fact that strain induced by the protein environment decreases the iron-iron distance.

As noted by Solomon et al., 90 it is difficult to understand the similarity between the optical absorption spectra of the peroxo species in $\mathrm{MMOH}$ and RNR-R2 given that they have different binding modes. One possibility is that two peroxide species may be formed along the $\mathrm{O}_{2}$ activation pathway. The energetics obtained in the current study and the sequence of structural and electronic changes that occur along the cycle are not inconsistent with such a hypothesis. Indeed, all our analyses of the $A \mu-1,2 \mathrm{H}_{\text {peroxo }}$ and the $\mu-\eta^{2}, \eta^{2}$ structures support the fact that the latter has a true peroxo nature whereas the former is intermediate between a superoxo and a peroxo species. The fact that $A \mu-1,2 \mathrm{H}_{\text {peroxo }}$ prevents a complete electron transfer to give a true peroxo species makes it a poor candidate for generating $\mathrm{H}_{\mathrm{Q}}$, which requires such a new electron transfer. In this context the $\mu-\eta^{2}, \eta^{2}$ structure appears to be a much better candidate for the intermediate preceding the formation of $\mathrm{H}_{\mathrm{Q}}$. Notably, a Q-type intermediate does not appear to form in ribonucleotide reductase. Possibly MMOB is involved in stabilizing the $\mathrm{H}_{\text {peroxo }}$ form that converts to $\mathrm{H}_{\mathrm{Q}}$. The possibility that two peroxo intermediates occur has been previously proposed by Lippard et al. ${ }^{23}$ to explain the discrepancy between the rates of formation of $\mathrm{H}_{\text {peroxo }}$ as determined by stopped-flow optical spectroscopy and by Mössbauer or optical spectroscopy.

To summarize, our QM/MM calculations are in better agreement with a $\mu-\eta^{2}, \eta^{2}$ structure for $\mathrm{H}_{\text {peroxo }}$ prior the formation of $\mathrm{H}_{\mathrm{Q}}$, and do not exclude the possible existence of another intermediate between $\mathrm{H}_{\text {superoxo }}$ and $\mathrm{H}_{\text {peroxo }}$ having the structure of $\mathrm{A} \mu-1,2 \mathrm{H}_{\text {peroxo }}$.

\section{QM/MM structure of $\mathrm{H}_{\mathbf{Q}}$}

The structure obtained for $\mathrm{H}_{\mathrm{Q}}$ in the current study features asymmetric coordination of the oxygen atoms that bridge the iron atoms, as was observed experimentally. ${ }^{31}$ This result is particularly interesting because our previous calculations at the QM level yielded a symmetric structure for the singlet state. The nonet state, very close in energy, was strongly asymmetric. This asymmetric structure was shown to be better described in terms of an $\mathrm{Fe}(\mathrm{III})-\mathrm{Fe}(\mathrm{V})$ diiron core, whereas the symmetric case was better represented as an $\mathrm{Fe}(\mathrm{IV})-\mathrm{Fe}(\mathrm{IV})$ diiron core. The protein environment, and most likely its electrostatic field, is probably responsible of some kind of mixing between these two oxidation state extrema. The calculations also demonstrate that the electronic structure of $\mathrm{H}_{\mathrm{Q}}$ is particularly sensitive to the chemical environment since the geometry of the diiron core changes depending on the coupling chosen for the diiron core, and whether or not the protein is included in the model. 


\section{Role of the protein in dioxygen activation}

The most interesting finding of the present $\mathrm{QM} / \mathrm{MM}$ calculations is that the protein seems to play an active role in the catalysis, principally by differentially compressing the $\mathrm{Fe}-\mathrm{Fe}$ distance for the various species in the catalytic cycle. This effect is consistently observed along the path from $\mathrm{H}_{\text {red }}$ to $\mathrm{H}_{\text {peroxo }}$ (Table 3). It has also been observed for $\mathrm{H}_{\text {red }}$ using ONIOM methods 50 but, whereas with our $\mathrm{QM} / \mathrm{MM}$ methodology the agreement with the experimental $\mathrm{Fe}-\mathrm{Fe}$ distance is very good $(\sim 0.02 \AA)$, the results with ONIOM method were significantly less accurate $(0.15-0.25 \AA)$, probably due to quantitative errors in the QM/MM interface model employed in ref. $\left[{ }^{50}\right]$.

From an energetic point of view, the effect of the protein is to decrease (make more negative relative to $\mathrm{H}_{\text {red }}$ ) the energy of species between $\mathrm{H}_{\text {red }}$ and $\mathrm{H}_{\text {peroxo }}$ (Table 5 and discussion on the $\mathrm{QM} / \mathrm{MM} / / \mathrm{RDFT}$ calculations in Supporting Information). It is therefore tempting to correlate stabilization with compression of the iron-iron distance. In this sense, the most reasonable explanation for the effect of the protein would be that it preferentially destabilizes $\mathrm{H}_{\text {red }}$ because the largest compression of the iron-iron distance is observed for this species. This strain energy is then released along the reaction pathway until arriving at $\mathrm{H}_{\text {peroxo. }}$. This hypothesis, previously suggested by several authors, ${ }^{41,} 49$ is strongly supported by our current results.

It is interesting that the protein appears to increase, rather than decrease, the Fe-Fe distance for our model of $\mathrm{H}_{\mathrm{Q}}$ (by $0.14 \AA$ ). From a physical point of view, this result is not necessarily inconsistent with the behavior of the remaining species; the gas phase Fe-Fe separation for $\mathrm{H}_{\mathrm{Q}}$ is substantially shorter than for any other structure, so if the protein forces are generated by an effective harmonic model with an implicit equilibrium distance intermediate between this value $(2.70 \AA)$ and the typical gas phase separation in the remaining species $(\sim 3.5 \AA)$, the observed results can easily be rationalized. It is beyond the scope of the present paper to analyze the protein forces in sufficient detail to establish whether this picture is correct, but such an investigation is possible in principle, and will be considered in future publications.

There is finally, as noted above, an apparently large discrepancy between the calculated $\mathrm{Fe}-\mathrm{Fe}$ distance for $\mathrm{H}_{\mathrm{Q}}(2.84 \AA)$ and the value extracted from analysis of EXAFS data in ref. $\left[{ }^{31}\right]$ ( 2.46 $\AA$ ). The excellent agreement that we now obtain for the structure of $\mathrm{H}_{\text {red }}$ with the crystallographic data of ref. $\left.{ }^{86}\right]$ provides some confidence that the B3LYP/QM/MM methodology employed herein is capable of generating accurate structural predictions, given a reasonable initial starting geometry and electronic wavefunction. At the moment, we have to regard this discrepancy as an unresolved problem, with a number of possible solutions: (1) the structure of $\mathrm{Q}$ might be qualitatively different from what we assume here (although we are not aware of other plausible candidate structures with competitive energies that have been proposed); (2) the binding of MMOB might significantly alter the active site geometry, resulting in the reduction of the Fe-Fe distance; (3) There may be some difficulties in the interpretation of the EXAFS data. All of these avenues will need to be pursued in order to achieve convergence of theory and experiment.

\section{Conclusion}

The present theoretical QM/MM models reveal how the protein matrix can influence the diiron active site of $\mathrm{MMOH}$ by compressing the iron-iron distance. The energetic consequences are that the intermediates closer to the reduced form in the proposed reaction pathway (Figure 11) are more destabilized by the protein than those closer to $\mathrm{H}_{\mathrm{Q}}$.

Different structures were investigated for $\mathrm{H}_{\text {peroxo }}$. The results obtained with QM/MM models reveal that the cis- $\mu-1,2 \mathrm{H}_{\text {peroxo }}$ is $2.8 \mathrm{kcal} / \mathrm{mol}$ higher in energy than the $\mu-\eta^{2}, \eta^{2} \mathrm{H}_{\text {peroxo }}$ structure. Electronic structure and frequency calculations revealed that the cis- $\mu-1,2 \mathrm{H}_{\text {peroxo }}$ 
species is intermediate between a superoxo and a peroxo species. These results suggest that a cis- $\mu-1,2 \mathrm{H}_{\text {peroxo }}$ intermediate could precede the formation of the $\mu-\eta^{2}, \eta^{2}$ butterfly structure.

Very close energies were found for the $\mu-\eta^{2}, \eta^{2} \mathrm{H}_{\text {peroxo }}$ and $\mathrm{H}_{\mathrm{Q}}$ intermediates. By applying the B3LYP-LOC scheme recently developed in our laboratory, we suggested that this result is a consequence of systematic errors in the B3LYP functional. Although preliminary results obtained by applying a highly approximate version of our B3LYP-LOC methodology to the problem are encouraging, further investigation will required to ascertain the quantitative value of these corrections.

\section{Supplementary Material}

Refer to Web version on PubMed Central for supplementary material.

\section{Acknowledgements}

This work was supported in part by grants from the NIH to RAF (GM40526) and SJL (GM32134). We thank Per Siegbahn for useful discussions concerning the relative energies of the $\mathrm{H}_{\text {peroxo }}$ and $\mathrm{H}_{\mathrm{Q}}$ intermediates and DR thanks Benjamin Gherman and Laurance Beauvais for their advice and for helpful discussions. This research was performed in part using the Molecular Science Computing Facility (MSCF) in the William R. Wiley Environmental Molecular Sciences Laboratory, a national scientific user facility sponsored by the U.S. Department of Energy's Office of Biological and Environmental Research and located at the Pacific Northwest National Laboratory, operated for the Department of Energy by Battelle. This work was partially supported by the National Center for Supercomputing Applications under CHE040019 and utilized the IBM pSeries 690.

\section{References}

1. Feig AL, Lippard SJ. Chem Rev 1994;94:759.

2. Liu KE, Lippard SJ. Adv Inorg Chem 1995;42:263.

3. Wallar BJ, Lipscomb JD. Chem Rev 1996;96:2625. [PubMed: 11848839]

4. Valentine AM, Lippard SJ. J Chem Soc Dalton Trans 1997:3925.

5. Deeth RJ, Dalton H. J Biol Inorg Chem 1998;3:302.

6. Whittington, DA.; Lippard, SJ. Handbook of metalloproteins. 2. John Wiley \& Sons; Chichester: 2001. Methane monooxygenase hydroxylase; p. 712

7. Kopp DA, Lippard SJ. Curr Opin Chem Biol 2002;6:568. [PubMed: 12413539]

8. Merkx M, Kopp DA, Sazinsky MH, Blazyk JL, Muller J, Lippard SJ. Angew Chem, Int Ed 2001;40:2782.

9. Merkx M, Lippard SJ. J Biol Chem 2002;277:5858. [PubMed: 11709550]

10. Crabtree RH. J Chem Soc, Dalton Trans 2001:2951.

11. Periana RA, Bhalla G, Tenn WJ, Young KJH, Liu XY, Mironov O, Jones CJ, Ziatdinov VR. J Mol Catal A 2004;220:7.

12. van Beilen JB, Funhoff EG. Curr Opin Biotechnol 2005;16:308. [PubMed: 15961032]

13. Friesner RA, Baik MH, Gherman BF, Guallar V, Wirstam M, Murphy RB, Lippard SJ. Coord Chem Rev 2003;238:267.

14. Baik MH, Newcomb M, Friesner RA, Lippard SJ. Chem Rev 2003;103:2385. [PubMed: 12797835]

15. Noodleman L, Lovell T, Han WG, Li J, Himo F. Chem Rev 2004;104:459. [PubMed: 14871132]

16. Siegbahn PEM. J Biol Inorg Chem 2001;6:27. [PubMed: 11191221]

17. Torrent M, Musaev DG, Basch H, Morokuma K. J Comput Chem 2002;23:59. [PubMed: 11913390]

18. Yoshizawa K. J Inorg Biochem 2000;78:23. [PubMed: 10714702]

19. Gherman BF, Baik MH, Lippard SJ, Friesner RA. J Am Chem Soc 2004;126:2978. [PubMed: 14995216]

20. Liu KE, Wang DL, Huynh BH, Edmondson DE, Salifoglou A, Lippard SJ. J Am Chem Soc 1994;116:7465. 
21. Liu KE, Valentine AM, Wang DL, Huynh BH, Edmondson DE, Salifoglou A, Lippard SJ. J Am Chem Soc 1995; 117:10174.

22. Liu KE, Valentine AM, Qiu D, Edmondson DE, Appelman EH, Spiro TG, Lippard SJ. J Am Chem Soc 1995; 117:4997.

23. Valentine AM, Stahl SS, Lippard SJ. J Am Chem Soc 1999;121:3876.

24. Lee SY, Lipscomb JD. Biochemistry 1999;38:4423. [PubMed: 10194363]

25. Brazeau BJ, Lipscomb JD. Biochemistry 2000;39:13503. [PubMed: 11063587]

26. Kim K, Lippard SJ. J Am Chem Soc 1996;118:4914.

27. Micklitz W, Bott SG, Bentsen JG, Lippard SJ. J Am Chem Soc 1989;111:372.

28. Menage S, Brennan BA, Juarezgarcia C, Münck E, Que L Jr. J Am Chem Soc 1990;112:6423.

29. Brennan BA, Chen QH, Juarezgarcia C, True AE, O'connor CJ, Que L Jr. Inorg Chem 1991;30:1937.

30. Lee SK, Fox BG, Froland WA, Lipscomb JD, Münck E. J Am Chem Soc 1993;115:6450.

31. Shu LJ, Nesheim JC, Kauffmann K, Münck E, Lipscomb JD, Que L Jr. Science 1997;275:515. [PubMed: 8999792]

32. Lee SK, Nesheim JC, Lipscomb JD. J Biol Chem 1993;268:21569. [PubMed: 8408008]

33. Priestley ND, Floss HG, Froland WA, Lipscomb JD, Williams PG, Morimoto H. J Am Chem Soc 1992;114:7561.

34. Shteinman AA. FEBS Lett 1995;362:5. [PubMed: 7698352]

35. Lipscomb JD, Que L Jr. J Biol Inorg Chem 1998;3:331.

36. Nordlander E, Andersson KK. J Biol Inorg Chem 1998;3:300.

37. Shteinman AA. J Biol Inorg Chem 1998;3:325.

38. Whittington DA, Valentine AM, Lippard SJ. J Biol Inorg Chem 1998;3:307.

39. Gherman BF, Goldberg SD, Cornish VW, Friesner RA. J Am Chem Soc 2004;126:7652. [PubMed: 15198613]

40. Valentine AM, Wilkinson B, Liu KE, Komar-Panicucci S, Priestley ND, Williams PG, Morimoto H, Floss HG, Lippard SJ. J Am Chem Soc 1997;119:1818.

41. Dunietz BD, Beachy MD, Cao YX, Whittington DA, Lippard SJ, Friesner RA. J Am Chem Soc 2000;122:2828.

42. Guallar V, Gherman BF, Miller WH, Lippard SJ, Friesner RA. J Am Chem Soc 2002;124:3377. [PubMed: 11916423]

43. Lovell T, Han WG, Liu TQ, Noodleman L. J Am Chem Soc 2002;124:5890. [PubMed: 12010064]

44. Lovell T, Li J, Noodleman L. Inorg Chem 2001;40:5251. [PubMed: 11559090]

45. Lovell T, Li J, Noodleman L. Inorg Chem 2001;40:5267. [PubMed: 11559091]

46. Torrent M, Musaev DG, Morokuma K. J Phys Chem B 2001;105:322.

47. Yoshizawa K, Hoffmann R. Inorg Chem 1996;35:2409. [PubMed: 11666447]

48. Yumura T, Yoshizawa K. Bull Chem Soc Jpn 2004;77:1305.

49. Torrent M, Vreven T, Musaev DG, Morokuma K, Farkas O, Schlegel HB. J Am Chem Soc 2002;124:192. [PubMed: 11782169]

50. Hoffmann M, Khavrutskii IV, Musaev DG, Morokuma K. Int J Quantum Chem 2004;99:972.

51. QSite 2.7 Schrödinger Inc., Portland OR, 2003.

52. Murphy RB, Philipp DM, Friesner RA. Chem Phys Lett 2000;321:113.

53. Murphy RB, Philipp DM, Friesner RA. J Comput Chem 2000;21:1442.

54. Philipp DM, Friesner RA. J Comput Chem 1999;20:1468.

55. Jaguar 5.5 Schrödinger, Inc.; Portland OR: 2003.

56. IMPACT 2.7 Schrödinger Inc.; Portland OR: 2003.

57. Banks JL, et al. J Comput Chem 2005;26:1752. [PubMed: 16211539]

58. Jorgensen WL, Maxwell DS, TiradoRives J. J Am Chem Soc 1996;118:11225.

59. Kaminski GA, Friesner RA, Tirado-Rives J, Jorgensen WL. J Phys Chem B 2001;105:6474.

60. Guallar V, Friesner RA. J Am Chem Soc 2004;126:8501. [PubMed: 15238007]

$J$ Am Chem Soc. Author manuscript; available in PMC 2008 August 17. 
61. Guallar V, Baik MH, Lippard SJ, Friesner RA. Proc Natl Acad Sci U S A 2003;100:6998. [PubMed: 12771375]

62. Wirstam M, Lippard SJ, Friesner RA. J Am Chem Soc 2003;125:3980. [PubMed: 12656634]

63. Guallar V, Jacobson M, McDermott A, Friesner RA. J Mol Biol 2004;337:227. [PubMed: 15001364]

64. QSite 4.0 alpha Schrödinger Inc.; Portland OR: 2005.

65. Gherman BF, Lippard SJ, Friesner RA. J Am Chem Soc 2005;127:1025. [PubMed: 15656641]

66. Parr, RG.; Yang, W. Density Functional Theory of Atoms and Molecules. Oxford University Press; New York: 1989.

67. Becke AD. J Chem Phys 1993;98:1372.

68. Johnson BG, Gill PMW, Pople JA. J Chem Phys 1993;98:5612.

69. Lee CT, Yang WT, Parr RG. Phys Rev B 1988;37:785.

70. Friesner RA, Dunietz BD. Acc Chem Res 2001;34:351. [PubMed: 11352713]

71. Friesner RA, Murphy RB, Beachy MD, Ringnalda MN, Pollard WT, Dunietz BD, Cao YX. J Phys Chem A 1999;103:1913.

72. Vacek G, Perry JK, Langlois JM. Chem Phys Lett 1999;310:189.

73. Mainz DT, Klicic JJ, Friesner RA, Langlois JM, Perry JK. J Comput Chem 1997;18:1863.

74. Hay PJ, Wadt WR. J Chem Phys 1985;82:270.

75. Hay PJ, Wadt WR. J Chem Phys 1985;82:299.

76. Wadt WR, Hay PJ. J Chem Phys 1985;82:284.

77. Dunning TH. J Chem Phys 1989;90:1007.

78. Friesner RA, Knoll E, Cao Y. J Chem Phys 2006;125:124107. [PubMed: 17014166]

79. Curtiss LA, Raghavachari K, Redfern PC, Rassolov V, Pople JA. J Chem Phys 1998;109:7764.

80. Rosenzweig AC, Frederick CA, Lippard SJ, Nordlund P. Nature 1993;366:537. [PubMed: 8255292]

81. Rosenzweig AC, Nordlund P, Takahara PM, Frederick CA, Lippard SJ. Chem Biol 1995;2:409.

82. Humphrey W, Dalke A, Schulten K. J Mol Graphics 1996;14:33.

83. Maestro 6.01 Schrödinger, Inc; Portland OR: 2003.

84. Fox BG, Surerus KK, Münck E, Lipscomb JD. J Biol Chem 1988;263:10553. [PubMed: 2839495]

85. Hendrich MP, Münck E, Fox BG, Lipscomb JD. J Am Chem Soc 1990;112:5861.

86. Fox BG, Hendrich MP, Surerus KK, Andersson KK, Froland WA, Lipscomb JD, Münck E. J Am Chem Soc 1993;115:3688.

87. Whittington DA, Lippard SJ. J Am Chem Soc 2001;123:827. [PubMed: 11456616]

88. Cramer CJ, Tolman WB, Theopold KH, Rheingold AL. Proc Natl Acad Sci U S A 2003;100:3635. [PubMed: 12634422]

89. Baik MH, Gherman BF, Friesner RA, Lippard SJ. J Am Chem Soc 2002;124:14608. [PubMed: 12465971]

90. Skulan AJ, Brunold TC, Baldwin J, Saleh L, Bollinger JM, Solomon EI. J Am Chem Soc 2004;126:8842. [PubMed: 15250738]

91. Dong YH, Yan SP, Young VG, Que L Jr. Angew Chem, Int Ed 1996;35:618.

92. Ookubo T, Sugimoto H, Nagayama T, Masuda H, Sato T, Tanaka K, Maeda Y, Okawa H, Hayashi Y, Uehara A, Suzuki M. J Am Chem Soc 1996;118:701.

93. Allen FH, Taylor R. Chem Soc Rev 2004;33:463. [PubMed: 15480471]

94. Scott AP, Radom L. J Phys Chem 1996;100:16502.

95. Suzuki M, Ishiguro T, Kozuka M, Nakamoto K. Inorg Chem 1981;20:1993.

96. Rohde JU, Torelli S, Shan XP, Lim MH, Klinker EJ, Kaizer J, Chen K, Nam WW, Que L Jr. J Am Chem Soc 2004;126:16750. [PubMed: 15612713]

97. Jensen MP, Costas M, Ho RYN, Kaizer J, Payeras AMI, Münck E, Que L Jr, Rohde JU, Stubna A. J Am Chem Soc 2005;127:10512. [PubMed: 16045338]

98. Siegbahn PEM. Inorg Chem 1999;38:2880. [PubMed: 11671034]

99. Torrent M, Mogi K, Basch H, Musaev DG, Morokuma K. J Phys Chem B 2001;105:8616.

100. Siegbahn PEM, Borowski T. Acc Chem Res 2006;39:729. [PubMed: 17042473]

$J$ Am Chem Soc. Author manuscript; available in PMC 2008 August 17. 


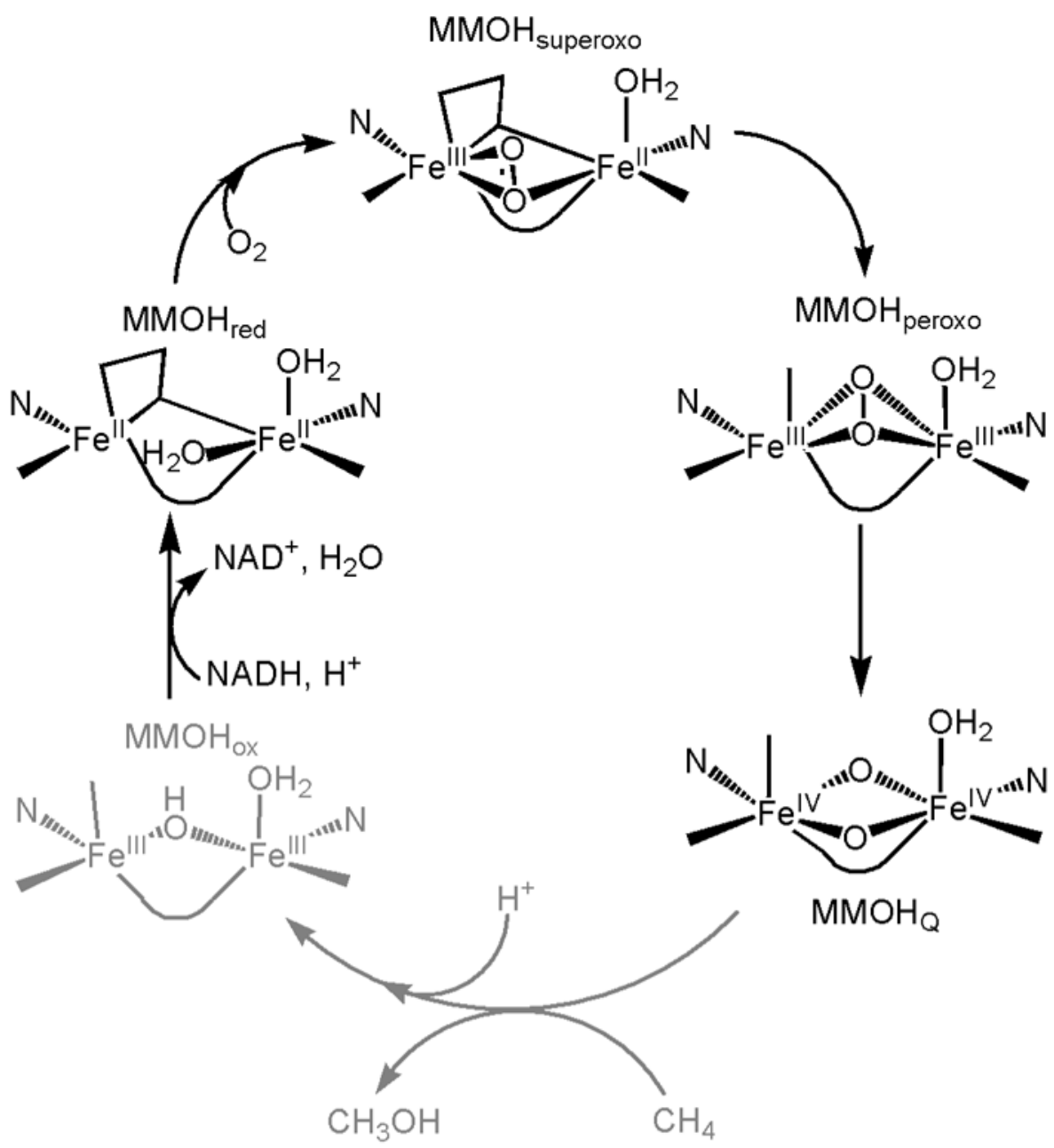

Figure 1.

The catalytic cycle of MMOH. The part of the cycle corresponding to activation of dioxygen is shown in black while the oxidation of the substrate (hydroxylation of methane into methanol in vivo) is in light gray. 


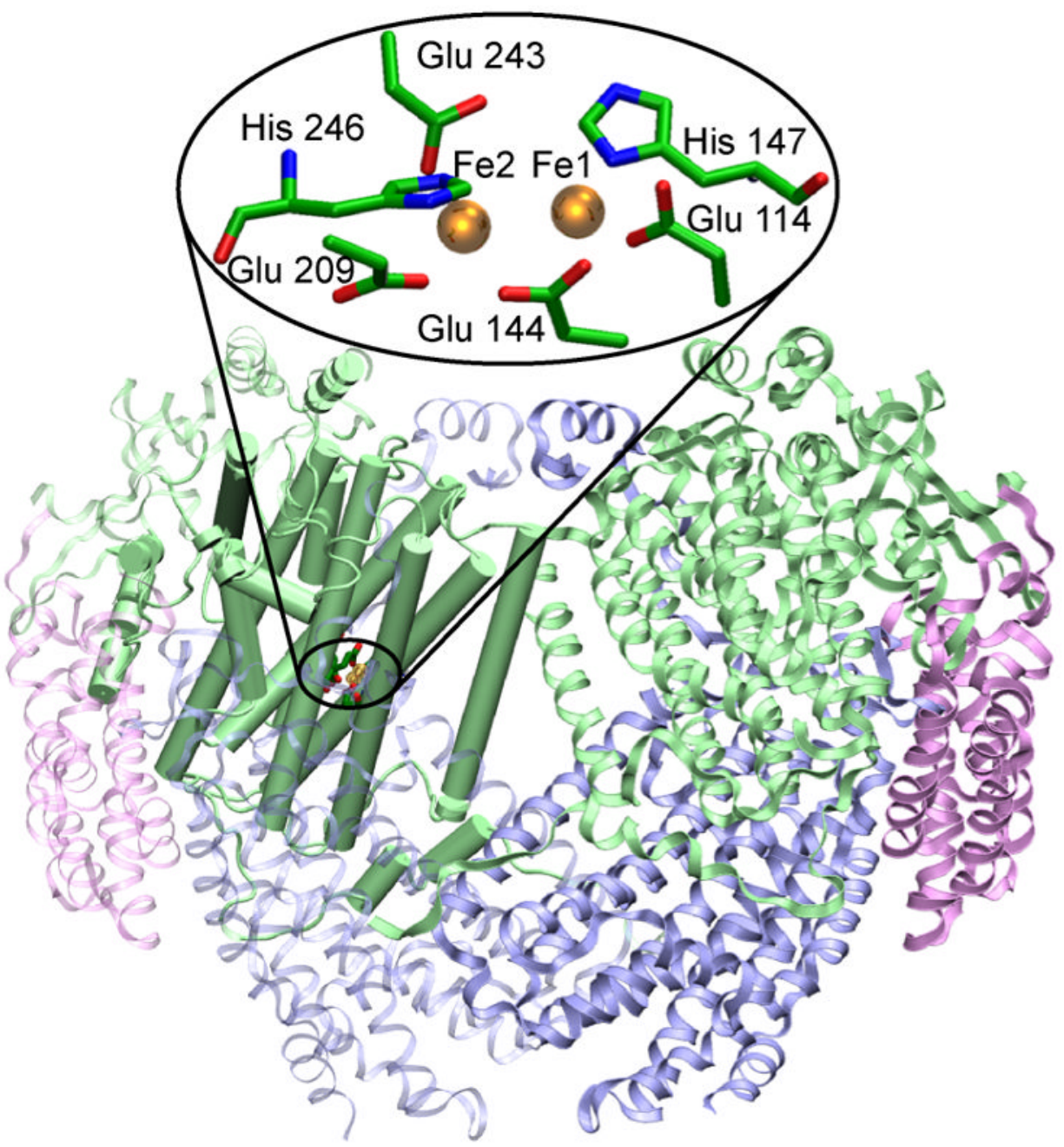

Figure 2.

Structure of the oxidized $\mathrm{MMOH}_{\mathrm{OX}}$ protein (PDB code 1MTY) represented in ribbon. The $\alpha$ subunits are depicted in green, the $\beta$ subunits in purple and the $\gamma$ subunits in pink. The QM/ MM model used is shown in cartoon representation and is made of a sphere of $35 \AA$ of the $\alpha$ subunit of protomer $\alpha$ (chain D in PDB code 1MTY). The QM part is represented in licorice in the panel (Graphic prepared with VMD ${ }^{82}$ ). Solvent-derived ligands are omitted. 


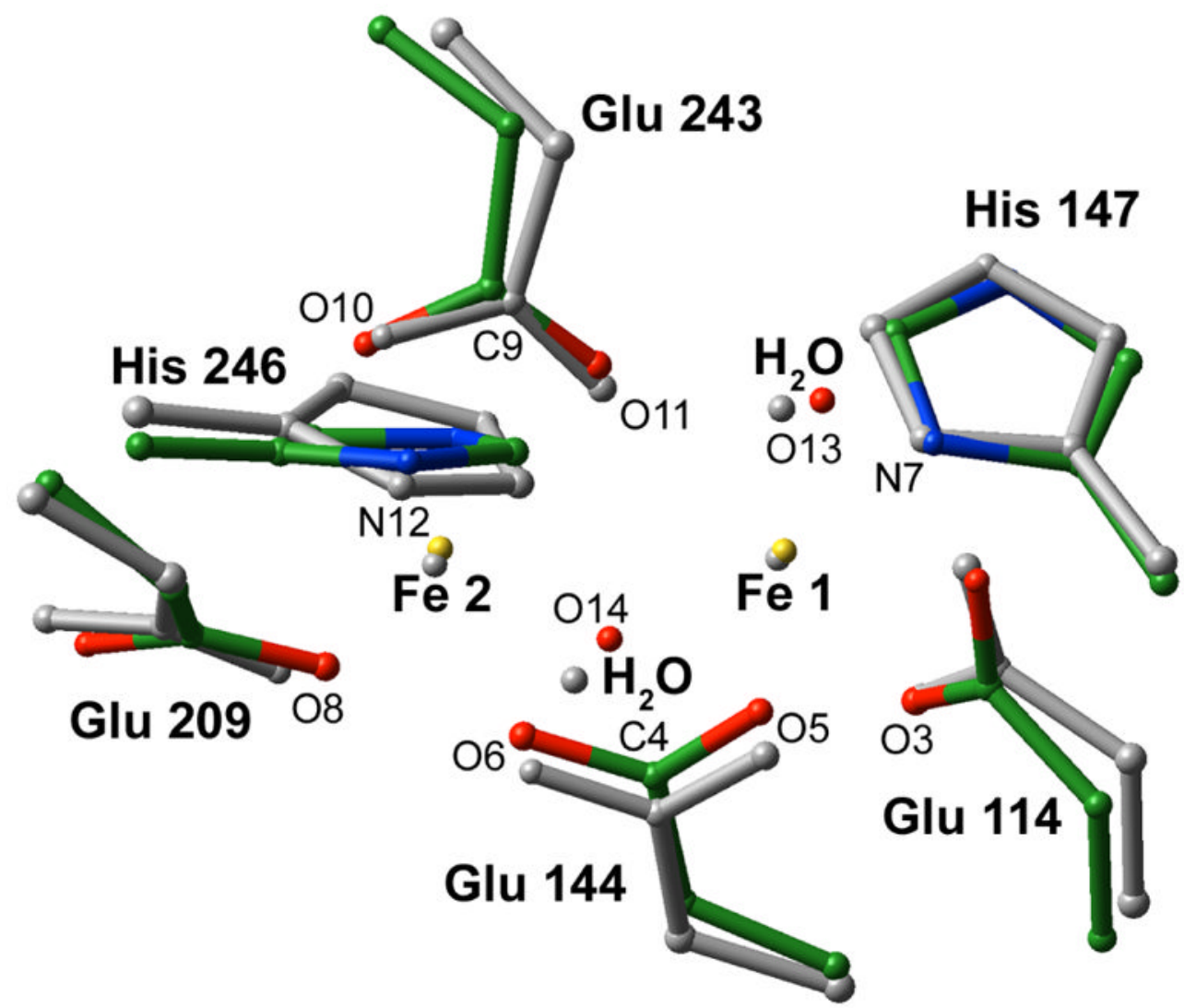

Figure 3.

Optimized QM/MM structure of Hred (color) superimposed onto the corresponding crystal structure (gray). The first shell atom names are also displayed. 


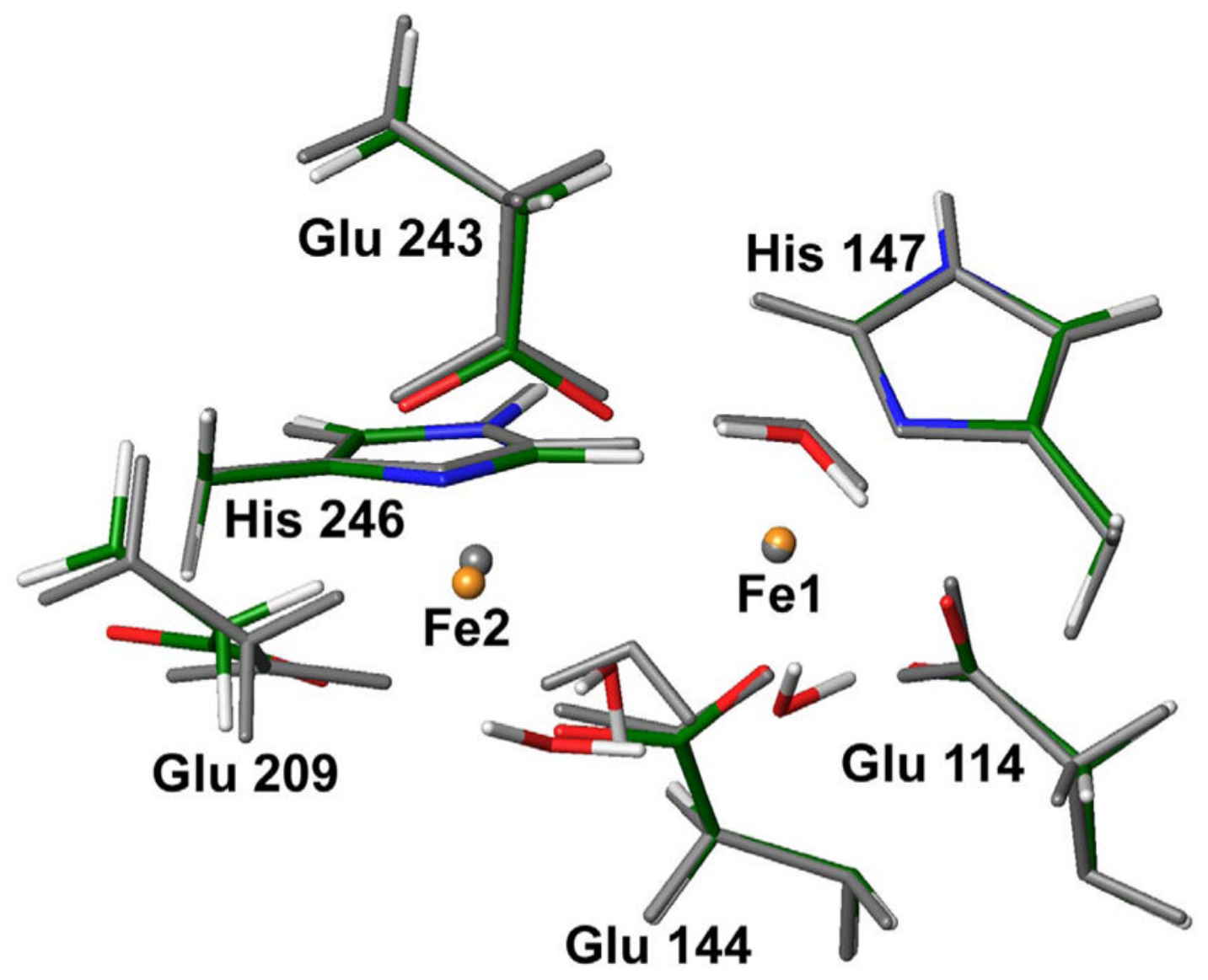

Figure 4.

QM/MM structure of Hred including two additional water molecules (color) superimposed onto the standard QM/MM model (gray). The two water molecules have an important effect on the position of Glu 209 and Fe2. 


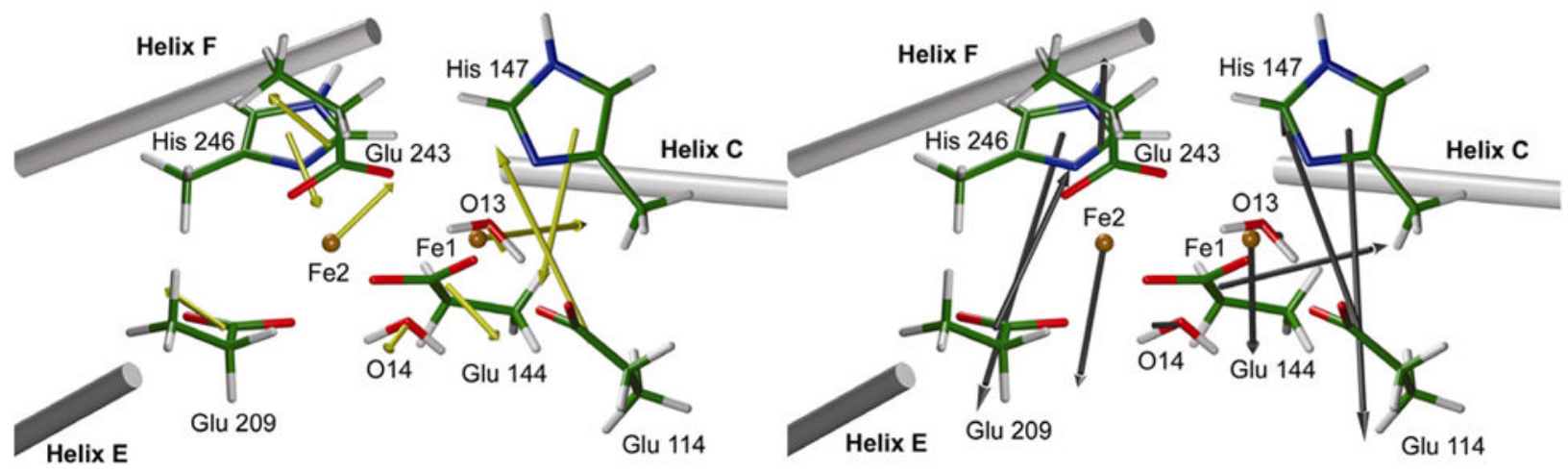

Helix B

Helix B

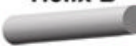

Figure 5.

Forces of the protein acting on the QM residues of the active site. On the left, forces correspond to the entire forces (QM forces calculation carried out in vacuum). On the right, forces correspond to what we call "tension forces", i.e. total forces minus the electrostatic forces of the protein (QM forces calculation with MM charge distribution of the protein included). 


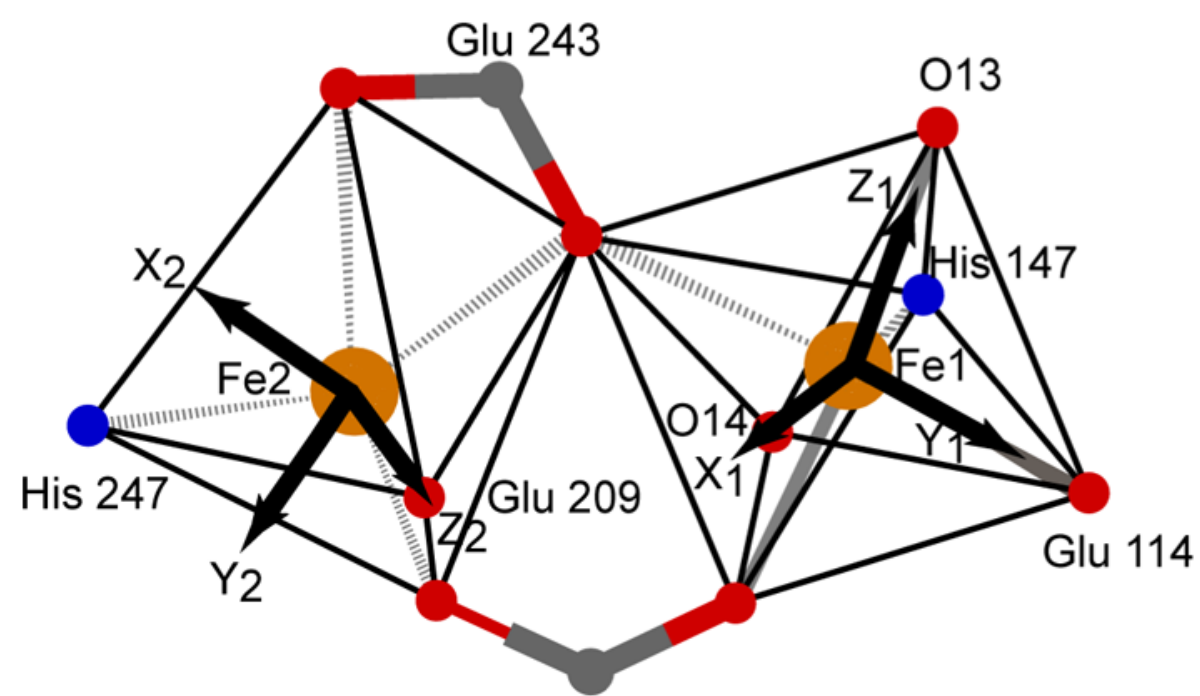

Glu 144

Figure 6.

Coordination geometries of the two iron atoms in the reduced state. Fe1 is in an octahedral environment, the axial direction of which is defined by the vector Glu 144-O13 ( $\mathrm{Z}_{1}$ vector). $\mathrm{Fe} 2$ is in a square pyramidal environment, the axial direction of which is defined by the Fe2Glu 209 direction $\left(Z_{2}\right.$ vector). Directions X1, Y1 and Z2 are oriented toward the front of the page. 

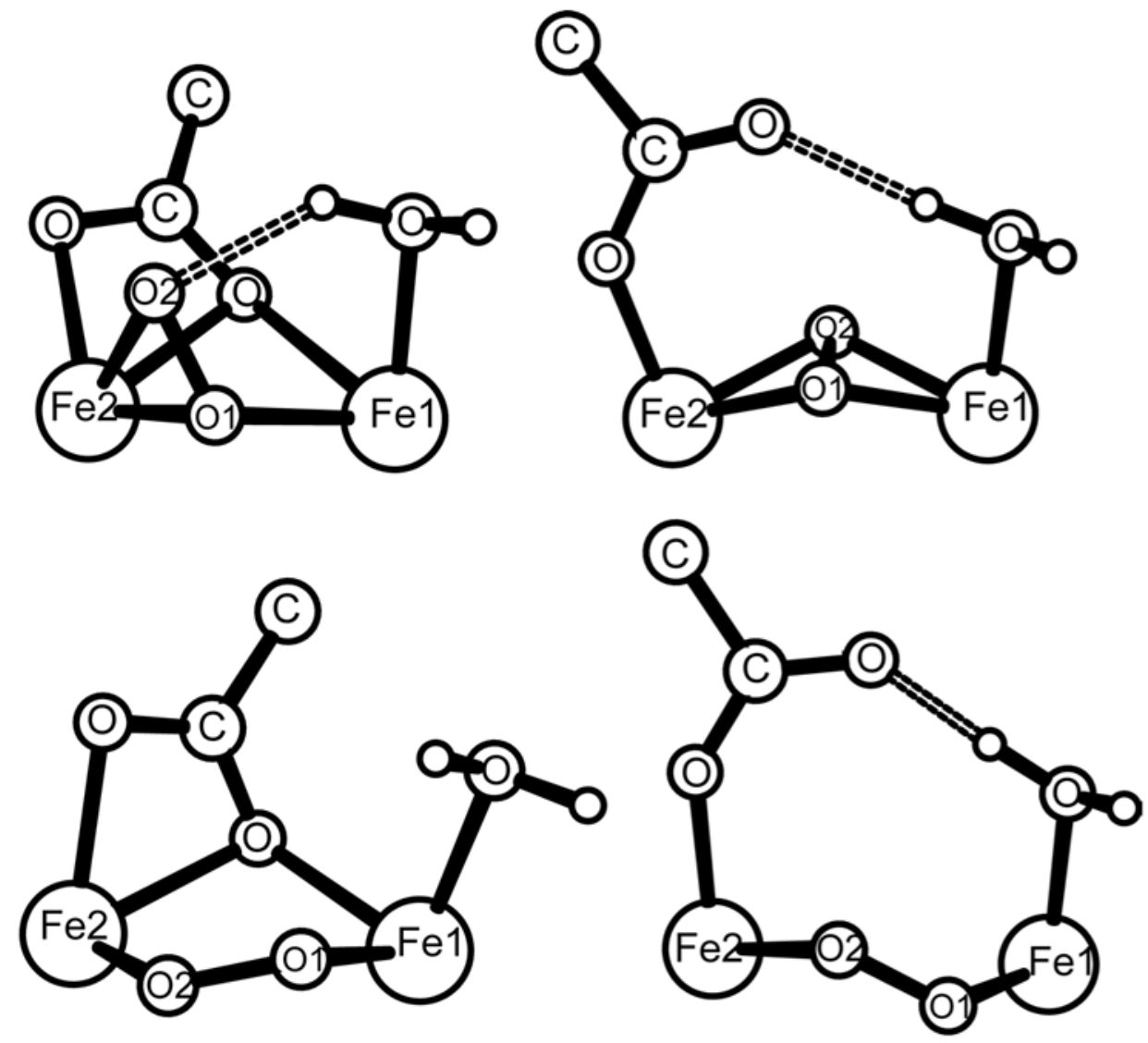

Figure 7.

Four tested geometries for $\mathrm{H}_{\text {peroxo }}$. In the upper left, the structure is similar to $\mathrm{H}_{\text {superoxo }}$ with a shifted Glu 243 and the peroxide coordinated to iron in a $\mu-\eta^{2}, \eta^{1}$ fashion. In the upper right, the peroxide adopts a $\mu-\eta^{2}, \eta^{2}$ butterfly arrangement. Both structures have been previously studied at the QM level. In the lower part, structures with peroxide coordinated to iron in a cis$\mu-1,2$ fashion are presented. On the left, the structure is similar to $H_{\text {superoxo }}$ with a shifted Glu $243\left(\mathrm{~A} \mu 12 \mathrm{H}_{\text {peroxo }}\right)$, while on the right $\left(\mathrm{S} \mu 12 \mathrm{H}_{\text {peroxo }}\right)$ it is similar to the $\mu-\eta^{2}, \eta^{2}$ butterfly peroxo arrangement with Glu 243 having the same conformation as in the crystal structure of the oxidized form. 


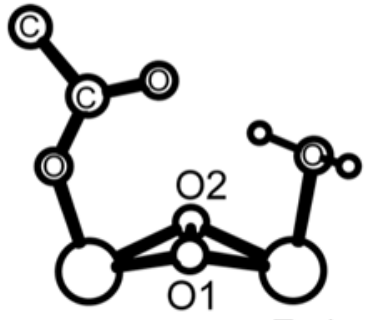

$\mathrm{Fe} 2$

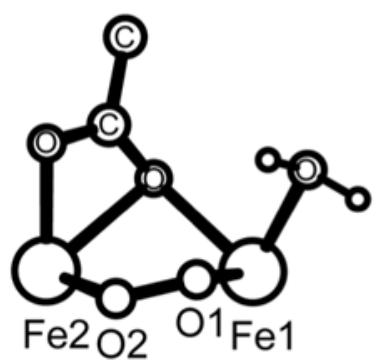

$\phi=-28.7^{\circ}$

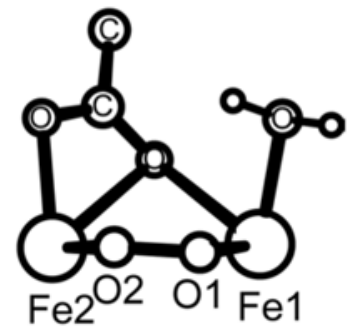

$\phi=-8.9^{\circ}$

$\phi=144.8^{\circ}$
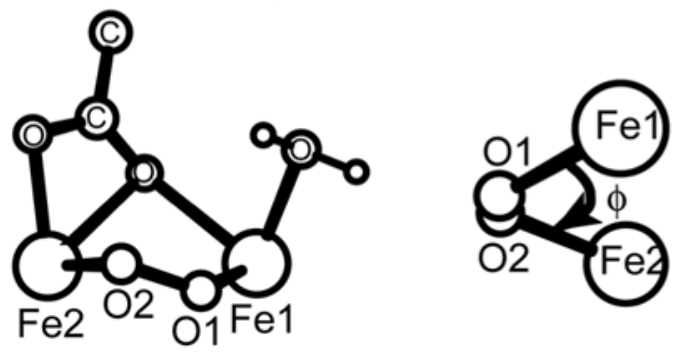

$\phi=42.1^{\circ}$

Figure 8.

Geometry of the $\mu-\eta^{2}, \eta^{2}$ butterfly structure of $H_{\text {peroxo }}$ and different conformers for the $A \mu-1,2$ $\mathrm{H}_{\text {peroxo }}$ structure. The dihedral angle between iron atoms and the peroxide moiety $(\varphi)$ is also defined (Fe1-O1-O2-Fe2). The first gauche conformation (top left) has a negative angle close to -30 and the second conformer has a positive one close to 40 . These two conformers have similar energies and have similar structures as those found in cis- $\mu-1,2$-peroxo model compounds. ${ }^{26}$ The last conformer (top right) is closer to the structures found in other cis$\mu$-1,2-peroxo model compounds. 91,92 


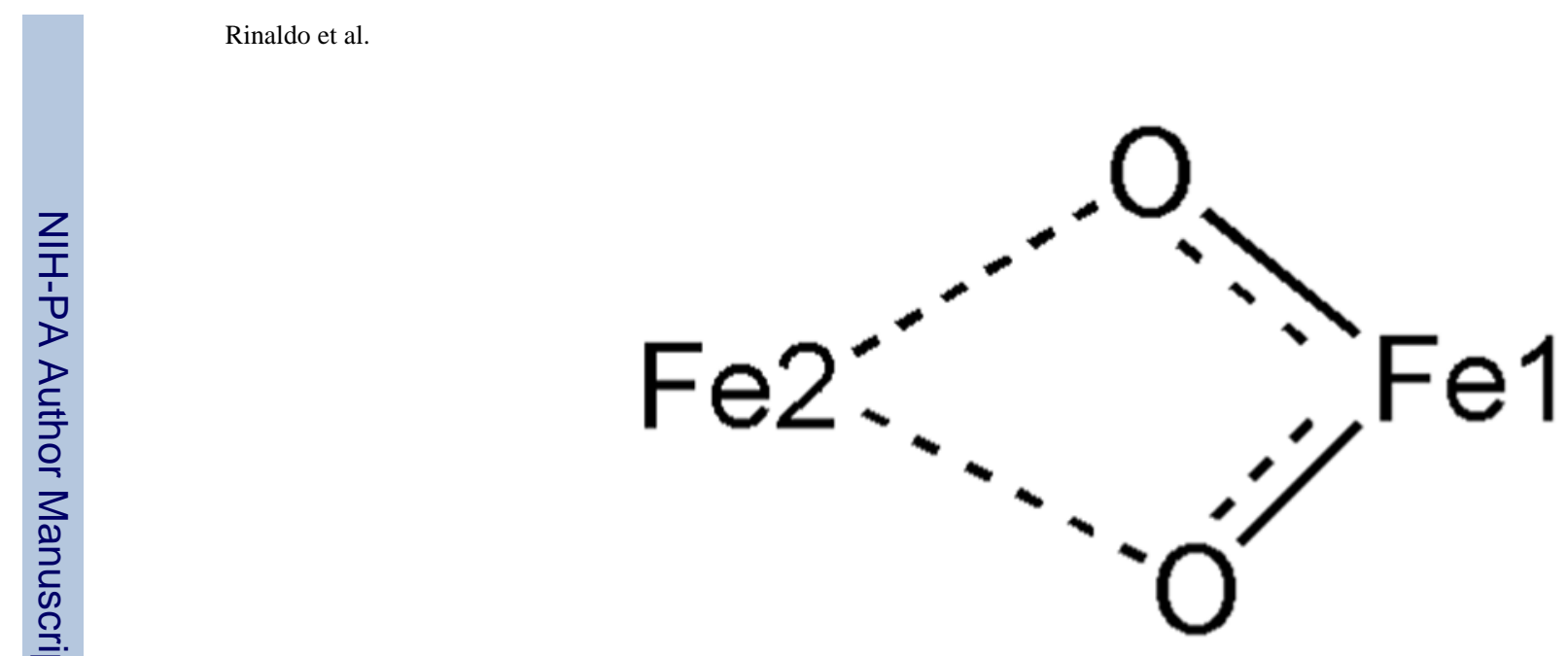

Figure 9.

Asymmetric structure for $\mathrm{H}_{\mathrm{Q}}$ derived from QM/MM calculations. 


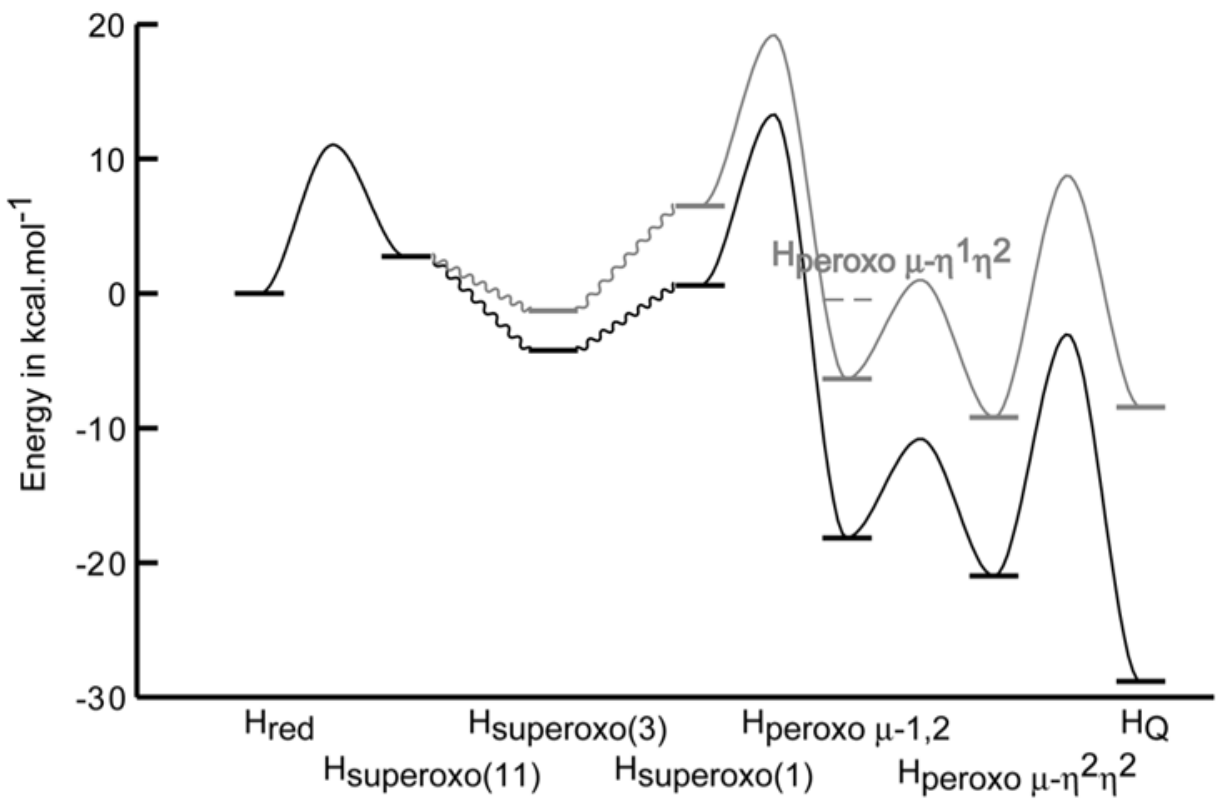

Figure 10.

Schematic reaction energy profile of the QM/MM intermediates as found with B3LYP (gray) and B3LYP-LOC (black). 


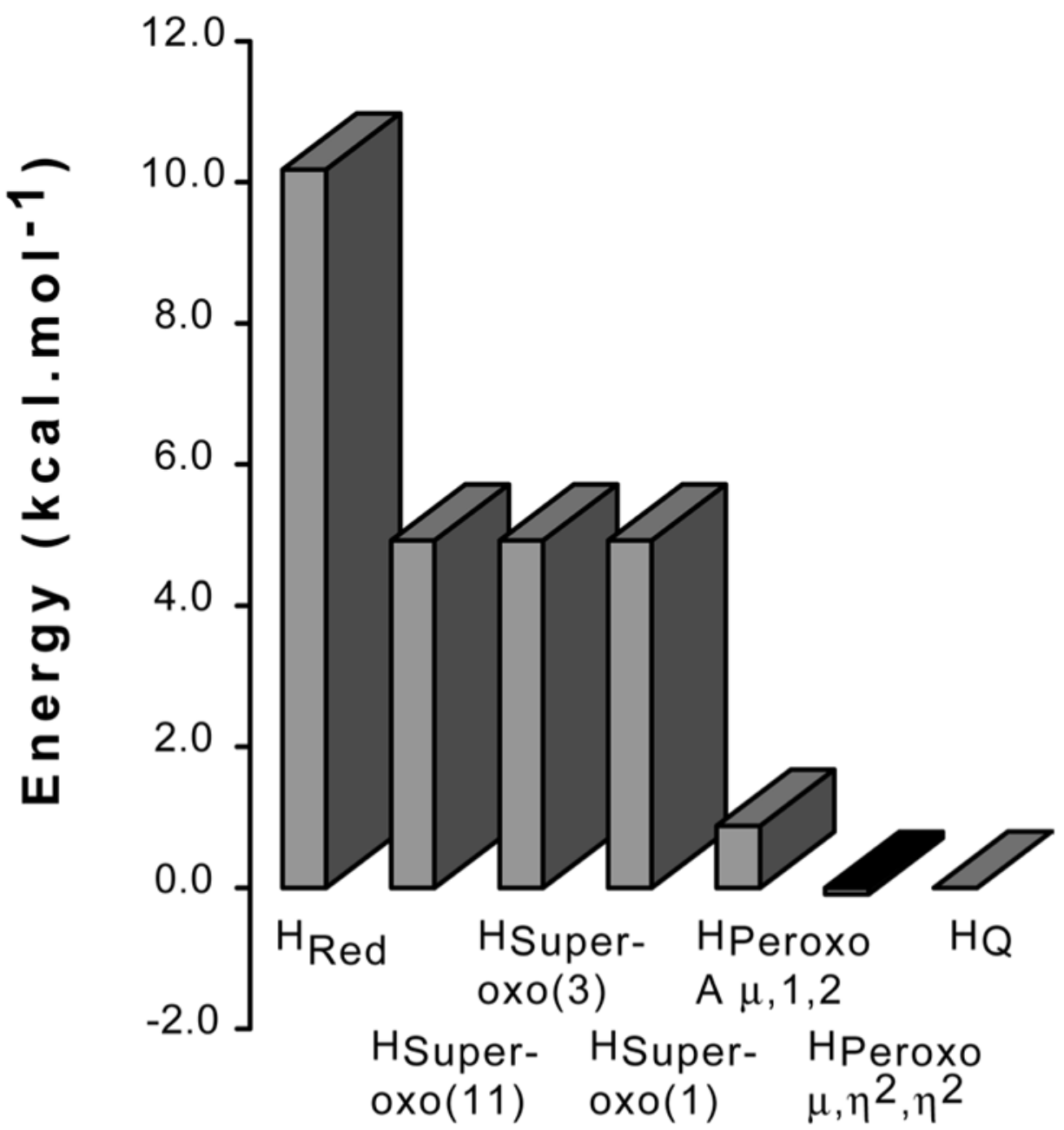

Figure 11.

Destabilization energies (in $\mathrm{kcal} / \mathrm{mol}$ ) due to the protein matrix computed from our QM/MM// RDFT models $\left(\Delta\left[\mathrm{E}_{\mathrm{QM} / \mathrm{MM}}-\mathrm{E}_{\mathrm{QM}-\mathrm{RODFT}}\right]\right.$ with $\mathrm{H}_{\mathrm{Q}}$ taken as a reference in Table $\mathrm{S}-4$ and discussion on the QM/MM//UDFT and QM/MM//RDFT in Supporting Information). The protein matrix effects destabilize more intermediates closer to the reduced form in the reaction pathway. 


$$
\mathrm{CH}_{4}+\mathrm{NADH}+\mathrm{H}^{+}+\mathrm{O}_{2} \longrightarrow \mathrm{CH}_{3} \mathrm{OH}+\mathrm{H}_{2} \mathrm{O}+\mathrm{NAD}^{+}
$$

Scheme 1. 


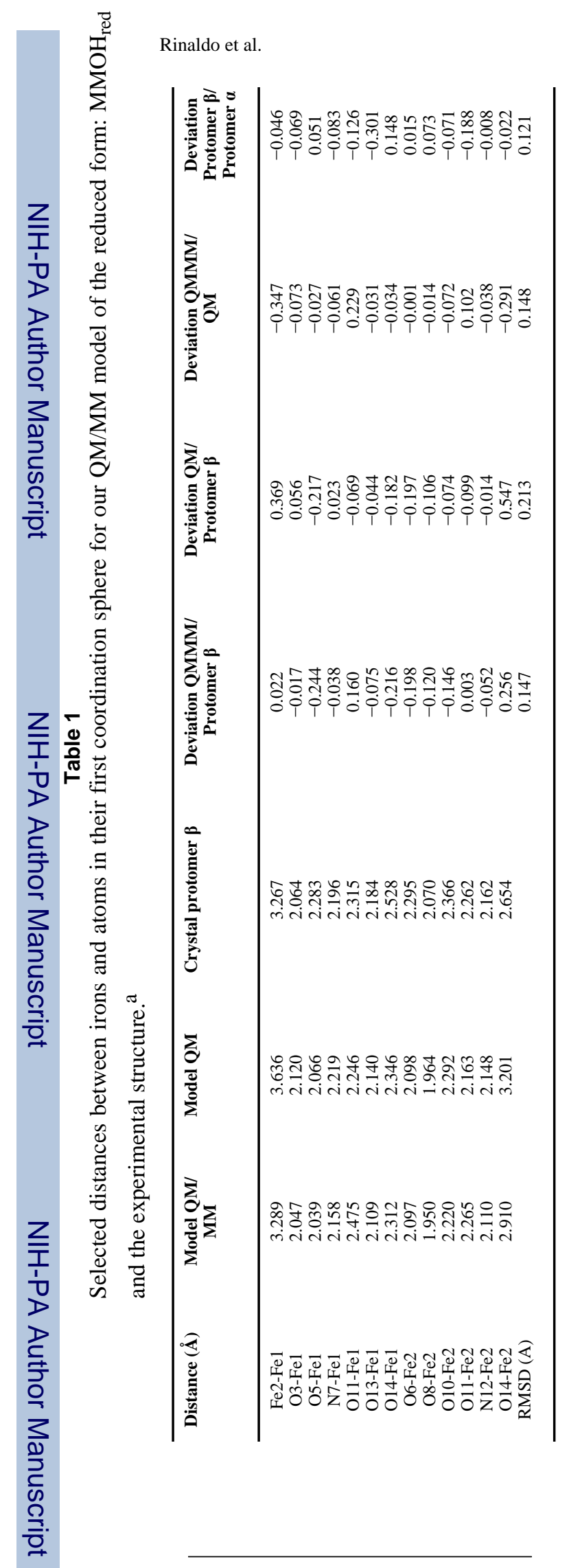

Page 30

${ }^{\text {a Experimental results are from structure PDB1FYZ }}{ }^{87}$ and atom numbering is shown in Figure 3.

$J$ Am Chem Soc. Author manuscript; available in PMC 2008 August 17. 
Table 2

Norms of the resultant of forces exerted by the protein on each residue of the active site in our QM/MM//RDFT model of the reduced form. ${ }^{b}$

\begin{tabular}{ccc}
\hline Residues & Total force in $\mathbf{m H a r t r e e / \text { Bohr }}$ & "Tension" force in mHartree/Bohr \\
\hline Glu 114 & 16.24 & 18.59 \\
Glu 144 & 6.76 & 15.14 \\
His 147 & 11.66 & 22.56 \\
Glu 209 & 6.74 & 12.71 \\
Glu 243 & 9.11 & 7.76 \\
His 246 & 9.84 & 23.79 \\
Fe1 & 13.16 & 10.39 \\
Fe2 & 6.29 & 11.61 \\
O13 & 2.74 & 3.17 \\
14 & 3.27 & 2.48 \\
\hline
\end{tabular}

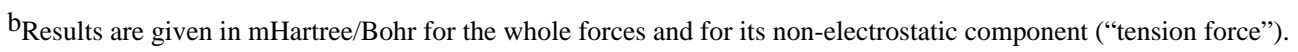


Table 3

Iron-Iron distances (in $\AA$ ) for intermediates as calculated with QM/MM models and with big models at the pure QM level. ${ }^{19 \mathrm{c}}$

\begin{tabular}{|c|c|c|c|c|}
\hline Species & $S_{z}\left(S_{z}+1\right)$ & QMM/MM & $\mathbf{Q M}$ & Difference \\
\hline $\mathrm{H}_{\text {red }}$ & 9 & 3.29 & 3.64 & 0.35 \\
\hline $\mathrm{H}_{\text {red-no-wat }}$ & 9 & 3.38 & 3.76 & 0.38 \\
\hline $\mathrm{H}_{\text {superoxo }}$ & 11 & 3.44 & 3.79 & 0.35 \\
\hline $\mathrm{H}_{\text {superoxo }}$ & 3 & 3.41 & 3.65 & 0.24 \\
\hline $\mathrm{H}_{\text {superoxo }}$ & 1 & 3.46 & 3.51 & 0.05 \\
\hline $\mathrm{H}_{\text {peroxo }}(\mu-\eta 2, \eta 2)$ & 1 & 3.48 & 3.61 & 0.13 \\
\hline $\mathrm{H}_{\text {peroxo }}(\mu-\eta 2, \eta 1)$ & 1 & 3.27 & 3.36 & 0.09 \\
\hline $\mathrm{H}_{\text {peroxo }}(\mathrm{A} \mu 12)^{*}$ & 1 & 3.47 & 3.57 & 0.10 \\
\hline $\mathrm{H}_{\text {peroxo }}(\mathrm{S} \mu 12)^{*}$ & 1 & 3.64 & 4.02 & 0.38 \\
\hline $\mathrm{H}_{\mathrm{Q}}^{*}$ & 1 & 2.84 & 2.70 & -0.14 \\
\hline
\end{tabular}

${ }^{\mathrm{c}}$ Results marked by a star were obtained with a medium model for pure QM calculations. The difference between the two models is also shown

J Am Chem Soc. Author manuscript; available in PMC 2008 August 17. 


\section{Table 4}

Summary of the frequencies for the $v(\mathrm{O}-\mathrm{O})$ and $v(\mathrm{Fe}-\mathrm{O})$ modes obtained from our theoretical models of A- $\mu 1,2$ $\mathrm{H}_{\text {peroxo }}$ and $\mu, \eta^{2}, \eta^{2} \mathrm{H}_{\text {peroxo. }}{ }^{\mathrm{d}}$

$$
\text { A- } \mu 1,2 \mathrm{H}_{\text {peroxo }}
$$

$\mathbf{v}\left({ }^{16} \mathrm{O}-{ }^{16} \mathrm{O}\right)\left(\mathrm{cm}^{-1}\right)$ 1004 (975)

$\mathrm{Fe}_{2}\left(\mu-\mathrm{O}_{2}\right)\left[\left(\mu-\mathrm{O}_{2} \mathrm{CPh}\right)\right]_{2}\left[\mathrm{HB}\left(\mathrm{pz}^{\prime}\right)_{3}\right]_{2}{ }^{26}$

$\mu, \eta^{2}, \eta^{2}, H_{\text {peroxo }}$

\begin{tabular}{c}
$\Delta\left[\begin{array}{c}\left.{ }^{\mathbf{1 8}} \mathbf{O}_{2}\right]\left(\mathbf{c m}^{-\mathbf{1}}\right) \\
48 \\
46\end{array}\right.$ \\
\hline
\end{tabular}

43.8
$\mathbf{v}\left(\mathrm{Fe}^{-16} \mathrm{O}\right)\left(\mathrm{cm}^{-1}\right)$ 441 (429)
415

544 (473)
$\Delta\left[{ }^{18} \mathrm{O}_{2}\right]\left(\mathrm{cm}^{-1}\right)$

20

11

$(2.8$

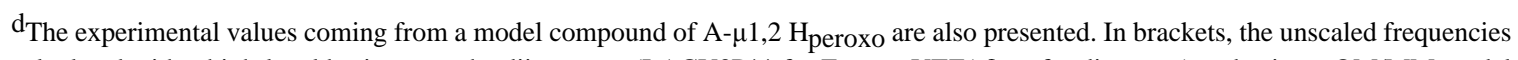
calculated with a high-level basis set on the diiron-core (LACV3P** for Fe, cc-pVTZ(-f)++ for dioxygen) and using a QM/MM model optimized at the same level are given.
} 


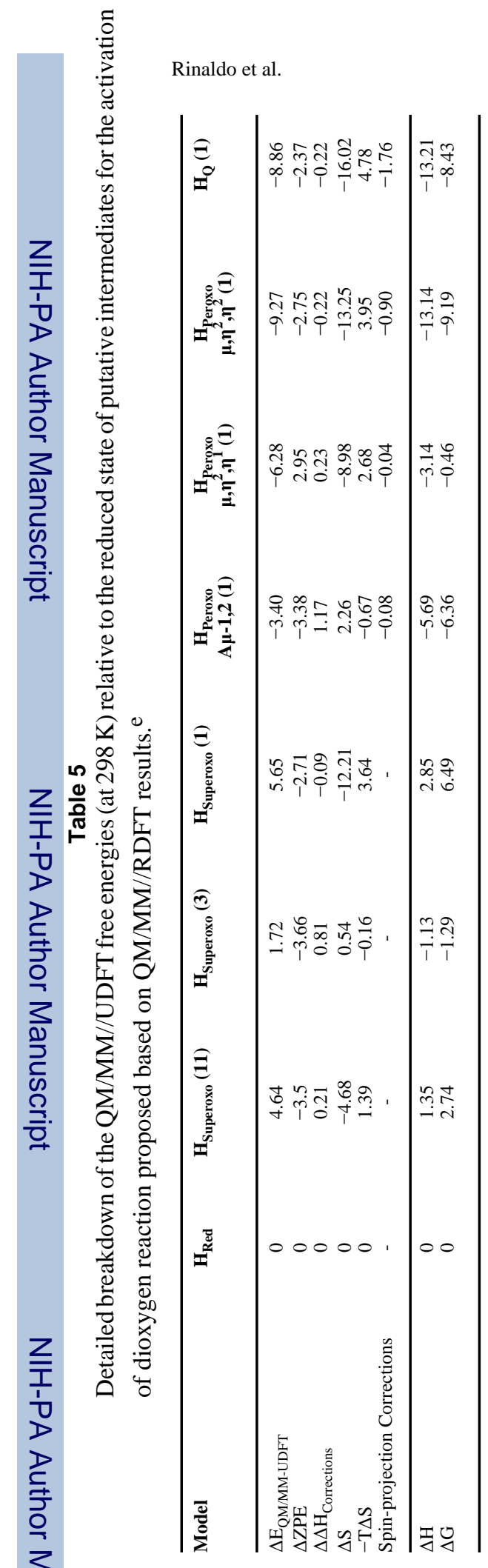

Page 34

e All energies are given in $\mathrm{kcal} / \mathrm{mol}$ except $\Delta \mathrm{S}$ which is given in cal $/ \mathrm{mol} \cdot \mathrm{K}$. Multiplicity of the state studied is written in brackets. ZPE, entropy and enthalpy corrections are based on pure QM frequency calculations. 
Table 6

Heisenberg exchange coupling constants (J) and corrections to the BS energies induced by spin projection for the QM/ MM model.

\begin{tabular}{lccc}
\hline Species & $\mathbf{S}_{\mathbf{z}}\left(\mathbf{S}_{\mathbf{z}}+\mathbf{1}\right)$ & $\mathbf{J}\left(\mathbf{c m}^{\mathbf{- 1}}\right)$ & $\Delta \mathbf{E}(\mathbf{k c a l} / \mathbf{m o l})$ \\
\hline $\mathrm{H}_{\text {Red }}$ & 9 & -25 & -0.29 \\
$\mathrm{H}_{\text {Red-no-wat }}$ & 9 & 23 & 0.26 \\
$\mathrm{H}_{\text {Peroxo }} \mathrm{A}(\mu-1,2)$ & 11 & -6 & -0.08 \\
$\mathrm{H}_{\text {peroxo }}\left(\mu-\eta^{2}, \eta^{1}\right)$ & 11 & -2 & -0.04 \\
$\mathrm{H}_{\text {peroxo }}\left(\mu-\eta^{2}, \eta^{2}\right)$ & 11 & -63 & -0.90 \\
$\mathrm{H}_{\mathrm{Q}}$ & 9 & -154 & -1.76 \\
\hline
\end{tabular}




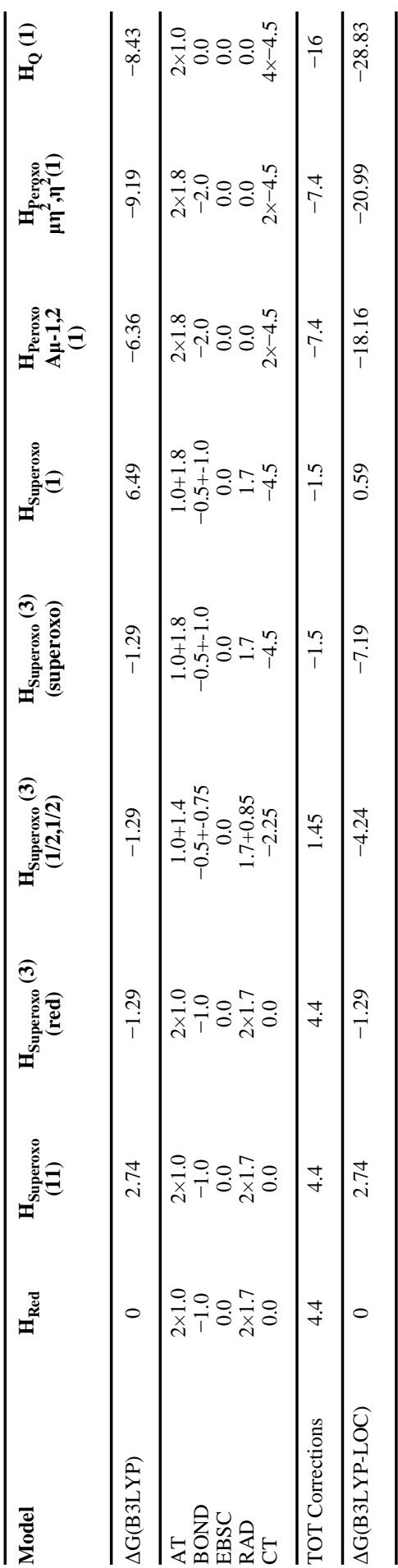

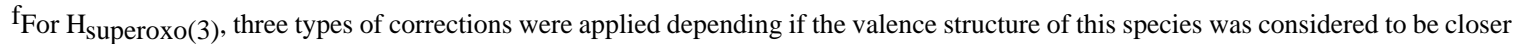
to the reduced state $\left(\mathrm{H}_{\text {superoxo(3) }}(\mathrm{red})\right)$, to the true superoxo state $\left(\mathrm{H}_{\text {superoxo(3) }}\right.$ (superoxo)) or just in between, thus requiring half corrections from $\mathrm{H}_{\text {reduced }}$ and half corrections from $\mathrm{H}_{\text {superoxo(1) }}\left(\mathrm{H}_{\text {superoxo(3) }}(1 / 2,1 / 2)\right)$. 